OPEN ACCESS

Edited by:

Emilia Morallon,

University of Alicante, Spain

Reviewed by:

Ramiro Ruiz Rosas,

University of Malaga, Spain Juan Manuel Sieben,

Universidad Nacional del Sur, Argentina

*Correspondence:

Vanessa Fierro

vanessa.fierro@univ-lorraine.fr

Specialty section:

This article was submitted to

Energy Materials,

a section of the journal

Frontiers in Materials

Received: 08 May 2020

Accepted: 12 June 2020

Published: 22 July 2020

Citation:

Castro-Gutiérrez J, Celzard A and Fierro V (2020) Energy Storage in

Supercapacitors: Focus on

Tannin-Derived Carbon Electrodes.

Front. Mater. 7:217.

doi: 10.3389/fmats.2020.00217

\section{Energy Storage in Supercapacitors: Focus on Tannin-Derived Carbon Electrodes}

\author{
Jimena Castro-Gutiérrez, Alain Celzard and Vanessa Fierro* \\ Université de Lorraine, CNRS, IJL, Epinal, France
}

Supercapacitors (SCs) are energy storage devices that bridge the gap between batteries and conventional capacitors. They can store more energy than capacitors and supply it at higher power outputs than batteries. These features, combined with high cyclability and long-term stability, make SCs attractive devices for energy storage. SCs are already present in many applications, either in combination with other energy storage devices (mainly batteries), or as autonomous energy sources. Porous carbons are presently used in the electrodes of commercial SCs due to their high surface area and their good conductivity. However, new porous materials are continuously being developed. Herein, an outline of the principles of the energy storage mechanism in SCs is presented as a guide to illustrate the research on porous carbons materials for SC applications. Indeed, an overview of these carbons and their synthesis methods is also presented. In the context of an urgent need to progress toward the development of environmentally friendly technologies and methods, the final part of this review focuses on the studies carried out using biosourced carbon precursors, such as tannins, which are natural polyphenolic molecules. In particular, mimosa tannin-derived carbon materials with controlled micro- and mesoporosity can be produced by methods with lower environmental impact and lower health and safety risks because crosslinkers are not needed to produce resins.

Keywords: supercapacitors, energy storage, porous carbons, OMCs, tannins

\section{INTRODUCTION}

World's electricity consumption has increased significantly in recent decades, from $\sim 11,000 \mathrm{TWh}$ in 1990 to 23,000 TWh in 2016, according to the International Energy Agency (IEA), and there is still a strong dependence on fossil fuels such as coal, oil and gas as energy sources (IEA, 2019). Furthermore, it is generally agreed that the increasing concentration of greenhouse gases in the atmosphere from the 1950s is partly attributable to the burning of fossil fuels, which is causing global climate change (Pachauri et al., 2015). The limits of fossil fuels reserves and the increasing global warming have amplified awareness on the need to phase out the fossil fuel industry. The transition to energy production from renewable sources and environmentally friendly technologies is a public demand. This poses a challenge for the production of electricity based on fluctuating energy sources such as solar or wind, among others. Thus, research aiming to improve the performance of energy storage devices is of great relevance nowadays. 
The role of energy storage devices in the electrical system is to collect excess of energy during high production peaks and act as a reservoir, releasing energy when required. Figure 1A lists some of the different storage technologies used at different steps of the electrical system (IEA, 2014; Aneke and Wang, 2016). Pumpedstorage hydropower and compressed air energy storage are widely used in electric power plants for large-scale production. On the other hand, batteries are suitable for a wider range of mid- and short-term storage applications such as distribution to remote sites, electric vehicles, small-scale production and off-grid storage for houses or buildings, and portable electronic devices also rely on battery use. On the contrary, supercapacitors (SCs) are high-power devices, meaning that they can supply stored energy at fast rates, and they are mostly used in short-term applications where bursts of electricity are needed.

SCs are presently used in a variety of applications, which could be further developed as stand-alone energy suppliers if their energy densities were increased (Sharma and Bhatti, 2010; Aneke and Wang, 2016; González et al., 2016; Wang et al., 2016). Accordingly, the international community has established the pursuit of improving the SCs performances as one of the short-term actions in the context of research and development on energy storage (IEA, 2014). This review is not intended to be exhaustive but to present a global vision of the principles underlying the energy storage mechanism in SCs, and to explain how these principles have guided the research of materials in this field, in particular for the production of carbon electrodes. Given the environmental issues mentioned above, the last part of this review incorporates studies using non-toxic and environmentally friendly carbon precursors, such as tannin extracts, to produce carbon electrodes for SCs.

\section{SUPERCAPACITORS}

\section{Basic Principles}

A SC consists of two parallel electrodes separated by a non-conductive material impregnated with an electrolyte, as illustrated in Figure 1B. By applying a potential between the electrodes, the ions in the electrolyte are attracted to the electrode of opposite charge. Derived from charge accumulation and the interaction with the electrode surface, an electrostatic doublelayer (EDL) is created on each electrode (González et al., 2016). Hence, there are two contributions to the total capacitance of the device, represented by the two capacitors in series shown in the simplified electric circuit of Figure 1B. An equivalent series resistance (ESR) is added to the circuit to account for the resistance of all the components of the device (Xie et al., 2018). The EDL generation process is ideally reversible, resulting in fast responses for charge and discharge, which result in high power in SCs. In addition, high cyclability, i.e., retention of capacitance after repetitive cycles of charge and discharge, and long lifetimes are achieved due to the low degradation of components derived from the reversibility of the EDL formation process.

From a macroscopic point of view, the capacitance $C$ of a SC can be calculated as in a regular capacitor of parallel plates:

$$
C=\frac{\varepsilon_{0} \varepsilon A}{d}
$$

where $\varepsilon_{0}$ is the permittivity of vacuum, $\varepsilon$ is the permittivity of the electrolyte, $A$ is the area of the electrode, and $d$ is the effective thickness of the EDL. The energy, $E$, of a capacitor is calculated as follows:

$$
E=\int C V d V
$$

where $V$ is the applied voltage to the device, also called potential window. For an ideal EDL SC, $C$ is not a function of $V$ and Equation (2) becomes:

$$
E=\frac{1}{2} C V^{2}
$$

The power, $P$, is then calculated through:

$$
P=\frac{E}{t_{d i s}}
$$

where $t_{\text {dis }}$ is the discharge time. Figure 2 shows a Ragone plot of typical values of energy and power of SCs compared to those of other energy storage devices such as batteries, fuel cells and capacitors.

\section{Applications}

The characteristic $E$ and $P$-values of SCs bridge the gap between conventional capacitors and batteries, as shown in Figure 2. Hence, SCs find their applications either as autonomous energy sources or in combination with other devices, as detailed below (Kötz and Carlen, 2000; Miller and Burke, 2008; Conte, 2010; Sharma and Bhatti, 2010; Gu and Yushin, 2014; Aneke and Wang, 2016; González et al., 2016; Gautham Prasad et al., 2019; IOXUS Inc, 2020; Maxwell Technologies Inc., 2020):

- Memory back-ups. Fast-response SCs are a short-term solution to a brief interruption of power supply to the memory.

- Portable tools. SCs are used as an energy source in camera flashes or portable screwdrivers, since only bursts of energy are required along with rapid and constant recharging.

- Distribution and storage of electrical energy. SCs are able to compensate short-duration voltage fluctuations in the distribution line and to match the variations between production and consumption. In addition, SCs are used to restart collapsed power systems or to supply energy until the primary source is restored. SCs are also used as storage devices in renewable energy production plants, especially in wind power applications, as they require little maintenance.

- Decoupling of power and energy needs. SCs are used to meet the power needs while the principal source of energy is provided by a different system. This type of decoupling is found in hybrid and electric vehicles. 
A
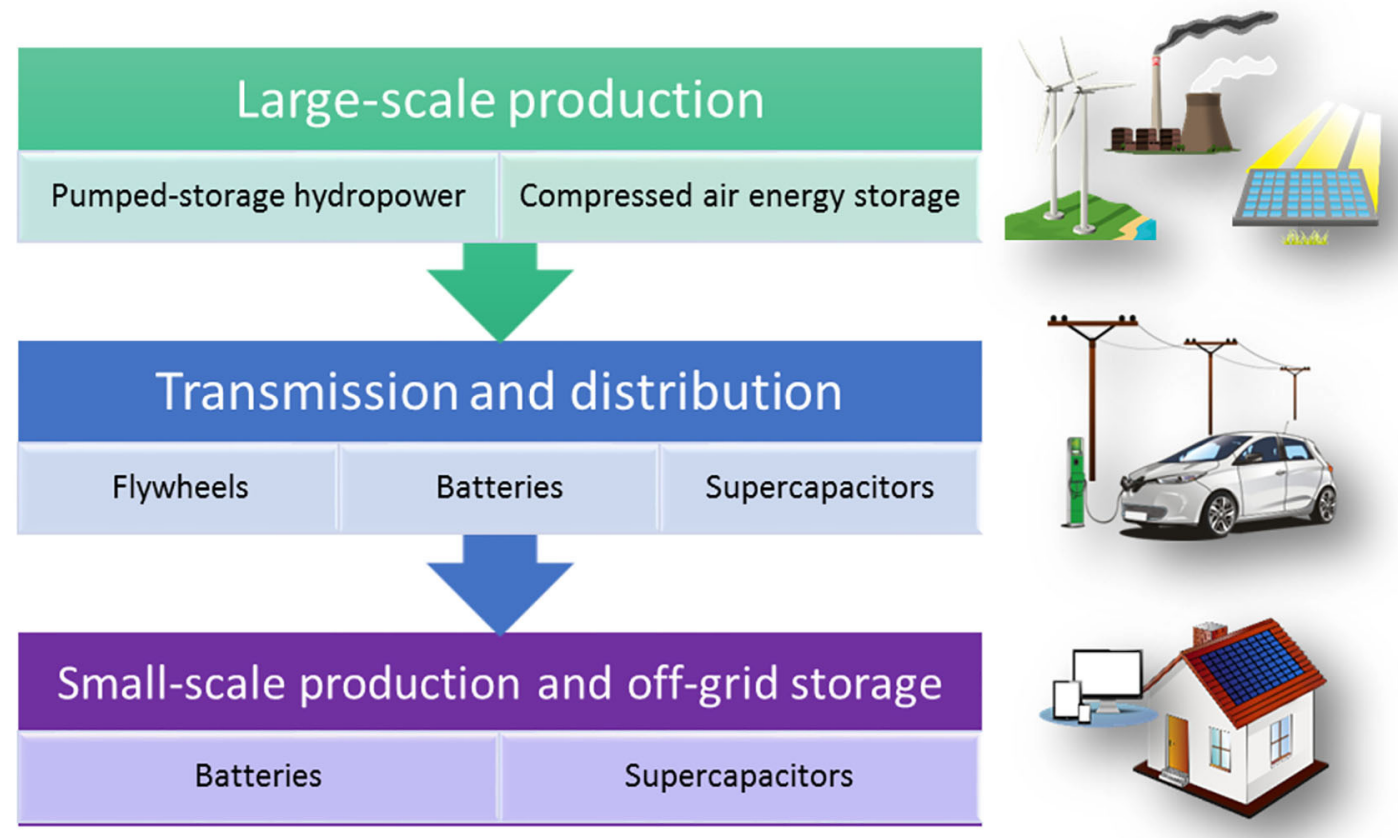

B

Discharged SC

$(\mathrm{V}=0)$

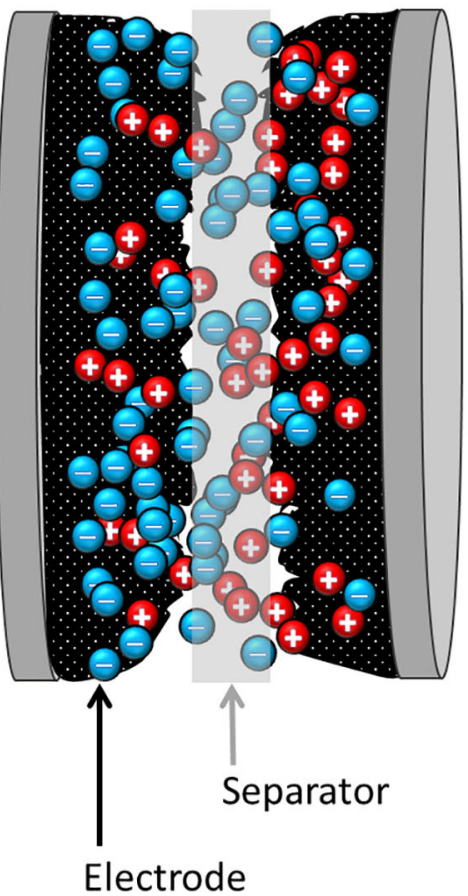

Charged SC

$(\mathrm{V}>0)$

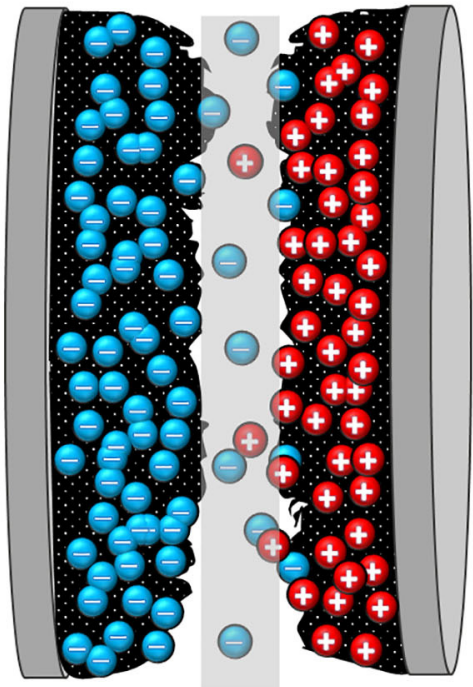

Electric circuit representation of a SC

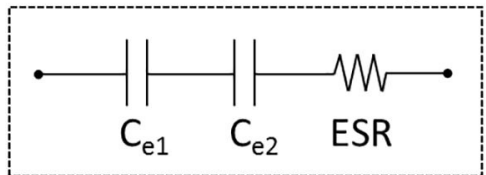

FIGURE 1 | (A) Energy storage technologies used at different scales in the power system (IEA, 2014; Aneke and Wang, 2016). (B) Mechanism of formation of the electrostatic double-layer (EDL) in a SC. In the associated electric circuit, capacitors $\mathrm{C}_{\mathrm{e} 1}$ and $\mathrm{C}_{\mathrm{e} 2}$ represent the contribution to the total capacitance of the EDL formed at the surface of each electrode. The equivalent series resistance (ESR) is also shown. 


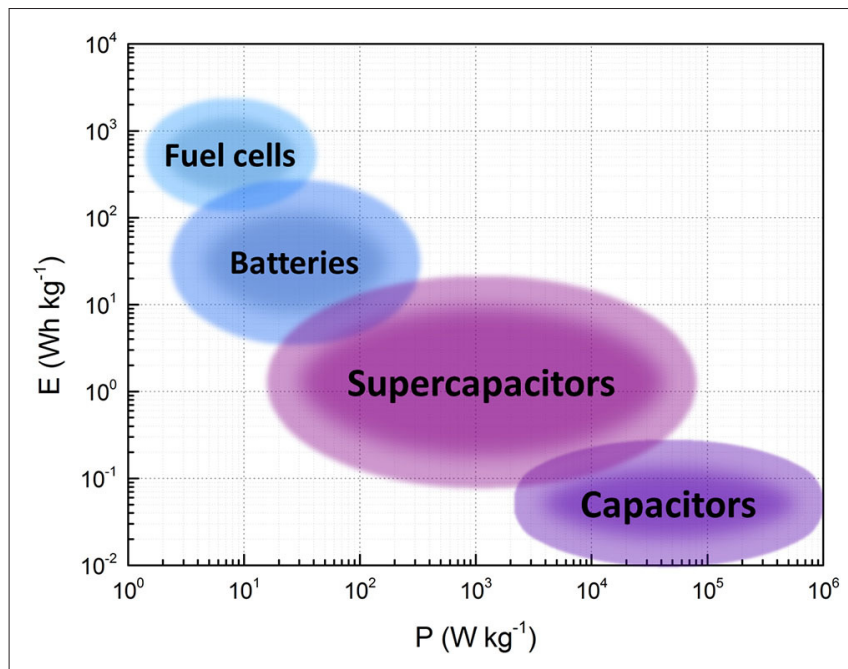

FIGURE 2 | Ragone plot showing the typical values of energy and power of different energy storage devices (Inamuddin et al., 2018).

- Regeneration devices. The energy released by machines with repetitive and constant movements can be recovered by SCs. Thus, SCs are found, for example, in cranes and elevators or in the braking systems of hybrid or electric vehicles like buses, delivery or garbage trucks and trains.

One of the main disadvantages of SCs compared to batteries is that they store less energy, which limits their use as autonomous devices. It is clear from Equation (3) that there are two ways to overcome this drawback: widening the potential window or increasing the capacitance. The former is strongly associated with the choice of electrolyte and the latter with the properties of the electrode. Nevertheless, they are intimately related to each other, because there must be a synergy between all the components of the SC. A clear example of this synergy is the pseudocapacitive behavior that some materials present when used as electrodes, where rapid Faradaic (redox) reactions occur on or near the surface of the electrode. The presence of redox reactions depends on the properties of the electrode material and on the affinity of the electrolyte toward it. SC devices with electrodes made of materials in which both EDL and pseudocapacitance storage mechanisms are present are also referred to as pseudocapacitors (PSCs) and could reach even higher values of capacitance. However, the increased capacitance in PSCs may be accompanied by a loss of power and long-term stability compared to that of SCs (González et al., 2016).

New materials are constantly being developed and their performance as electrodes for SCs must be evaluated. In the following section, the electrochemical testing techniques commonly used on a laboratory scale are briefly described in order to illustrate the expected behavior of a SC. Next, the types and general characteristics of commonly used electrolytes and the advances in the research for porous materials as electrodes for SCs are discussed.

\section{Electrochemical Testing Techniques Cell Configuration}

Figure 3 shows schemes of cell configurations normally used for SC testing. The three-electrode cells (Figure 3A) are useful for estimating the contributions of pseudocapacitance or for better understanding the more fundamental behavior of materials, while the two-electrode cells (Figure 3B) are used to evaluate the performance of materials in operating conditions closer to those of real SC devices (Xie et al., 2018). T-type cells are a combination of two- and three-electrode cell configurations (Figure 3C), which allow studying the performance of each electrode in a SC along with the performance of the whole system operating at the equilibrium potential of both electrodes (Sevilla et al., 2019). Thus, a three-electrode configuration measures the performance of a single electrode (the working electrode in Figure 3A), whereas a two-electrode configuration evaluates the performance of two electrodes as a system (the cell). As shown in Figure 1B, in a symmetric SC, the two electrodes are made of the same material and, based on the associated simplified circuit, its capacitance, $C$, can be calculated assuming that the contribution of each electrode is identical, i.e., $C_{e 1}=C_{e 2}=C_{e}$. Therefore:

$$
\begin{aligned}
\frac{1}{C} & =\frac{1}{C_{e}}+\frac{1}{C_{e}} \\
C & =\frac{C_{e}}{2}
\end{aligned}
$$

Reporting normalized values of capacitance allows for the comparison of results from different studies. Thus, from Equation (6) and considering that the normalization factor of the cell is twice the normalization factor of an electrode, i.e., $N=2 N_{e}$ (Zuliani et al., 2015):

$$
C_{N}=\frac{C}{N}=\frac{C_{e}}{2 N}=\frac{C_{e}}{4 N_{e}}=\frac{C_{e, N_{e}}}{4}
$$

$N$ is generally chosen to be either the mass or the volume of the electrodes. For simplicity, from now on, $C$ and $C_{e}$ will refer to the capacitances normalized by the mass of the electrode(s), called specific cell capacitance and specific electrode capacitance, respectively.

Many of the materials that can be used as electrodes for SCs are in powder form, so it is necessary to use a binder to agglomerate the powder particles and create a paste, or slurry, from which the electrodes are obtained. Some additives can also be mixed with the active material to improve their electrical conductivity. A correct assessment of the materials performance requires giving the calculations of normalized capacitance as a function of the total mass or the total volume of the electrode, i.e., including binder and/or the additives.

\section{Cyclic Voltammetry (CV)}

During cyclic voltammetry $(\mathrm{CV})$ tests, a potential $(V)$ is applied and increased at constant rate over time (scan rate) while the current response, $I$, is measured. An ideal SC would exhibit a rectangular curve when $I$ is plotted as a function of $V$, see 


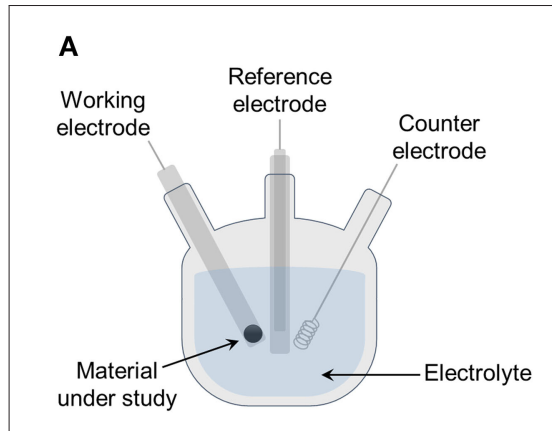

B

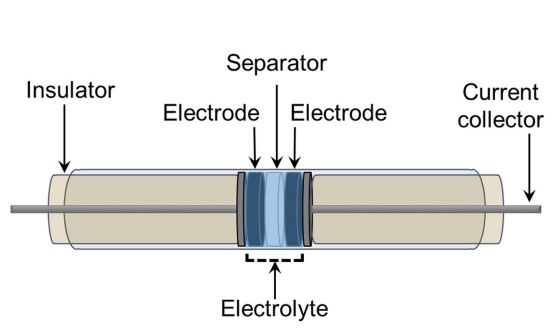

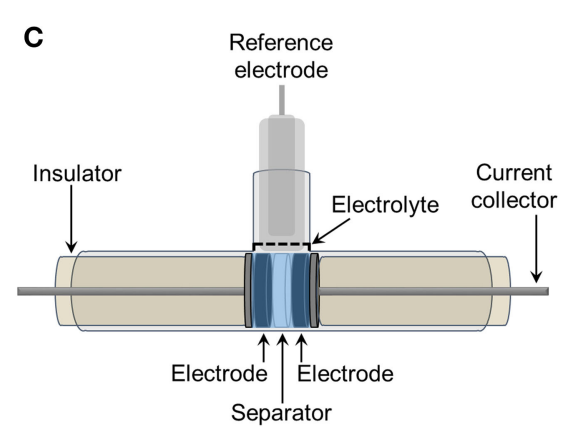

FIGURE 3 | Different configurations for the electrochemical characterization of SCs: (A) three-electrode cell, (B) two-electrode cell, and (C) T-type cell.

Figure 4A. During charging, the sharp increase in $I$ at the beginning of the cycle is due to the rapid formation of the EDL and it remains constant when $V$ increases because no Faradaic reaction occurs. Given the reversible nature of the EDL formation mechanism, the $\mathrm{CV}$ curve during discharge obtained when $V$ decreases is the exact inverse of the charging curve. Evidently, the CV curves of the real SCs deviate from the ideal one, and those of PSCs also display $I$ peaks due to the generation of charge by redox reactions, as shown in Figure 4A. In addition, widening the potential window in $\mathrm{CV}$ measurements allows identifying the point at which decomposition of the electrolyte occurs, manifesting by an I peak at each edge of the CV curve. Then, this information can be used to set the operating voltage of a SC cell. From CV data, $C$ is calculated by:

$$
C=\frac{\oint I d V}{2 s V m}
$$

where the numerator is the area delimited by the CV curve, $s$ is the scan rate, $V$ is the potential window and $m$ is the sum of the masses of the two electrodes in the cell. If a three-electrode configuration is used, $C_{e}$ can be calculated by substituting $m$ in Equation (8) for the mass of the working electrode, $m_{e}$.

\section{Galvanostatic Charge-Discharge (GCD)}

In the galvanostatic charge-discharge (GCD) technique, a constant $I$ is applied to the system while the response $V$ is recorded as a function of time. The method is normally carried out with a two-electrode configuration. In an ideal SC, charge and discharge have a linear mirror behavior, resulting in triangular curves. In real SCs and PSCs, the curves deviate from the linear behavior, see Figure 4B. Any device will exhibit a sudden drop in potential during the transition from charge to discharge. This is called IR drop and it is directly associated with the ESR of the device. From GCD data, $C$ is calculated by:

$$
C=\frac{I}{(\Delta V / \Delta t) m}
$$

where $I$ is the constant current applied, $\Delta V / \Delta t$ is the slope of the discharge curve and $m$ is the sum of the masses of the two electrodes in the SC. $C_{e}$ can then be approximated using Equation (7). Using this value of $C$, those of $E$ and $P$ of the SC can be calculated directly from Equations (3) and (4), respectively, keeping in mind that $V$ in Equation (3) is the actual operating potential, therefore the IR drop must be subtracted from the maximum potential reached by the cell, i.e., $V=V_{\max }-I R_{d r o p}$.

GCD tests performed at increasing values of $I$ provide insight into the kinetic behavior of the materials at faster charging rates. Although this can also be evaluated by increasing the scan rate in CV tests, GCD tests are preferred for kinetic analysis because the operating conditions are closer to those of real devices (Beguin and Frackowiak, 2013; Xie et al., 2018).

\section{Electrochemical Impedance Spectroscopy (EIS)}

Electrochemical impedance spectroscopy (EIS) is used to analyze the response of a material to a low-amplitude oscillating potential signal. A Nyquist plot represents the real and imaginary parts of the complex impedance, $Z_{r}$ and $Z_{i}$, respectively. Examples of curves obtained for an ideal SC, a real SC and a PSC are shown in Figure 4C. Analysis of Nyquist plots allows associating an equivalent circuit for each type of device, see Figures $4 \mathrm{E}-\mathrm{G}$, which provides information on the electrochemical system (Bard and Faulkner, 2001; Beguin and Frackowiak, 2013; Xie et al., 2018). For instance, a straight vertical line appears for a material with an ideal SC behavior. Its point of intersection with the $Z_{r}$ axis represents the value of the ESR of the device, $R_{s}$. The pseudocapacitive behavior adds a second charge transfer resistance to the system, $R_{c t}$, and a semicircle is observed in the Nyquist plot at high frequencies $\left(\mathrm{HF},>\sim 10^{3} \mathrm{~Hz}\right.$ ). In porous materials, the limited ion diffusion within the pores is modeled in the equivalent circuit as a constant phase element, $Z_{C P E}$, and it manifests itself in the Nyquist plot as a straight line in the HF for a SC and after the semicircle for the PSC (Beguin and Frackowiak, 2013). The longer the line, the more difficult it is for the electrolyte to access the whole surface of the material. Once the surface is completely impregnated, the capacitance no longer depends on the frequency, hence the vertical line appearing at low frequencies ( $\mathrm{LF}, \sim 10^{-3} \mathrm{~Hz}$ ). In all cases, the intersection with the $Z_{r}$ axis of the vertical line at LF is defined as the equivalent distributed resistance (EDR) that takes into account the ESR and the charge transfer and ion diffusion resistance of the material. 


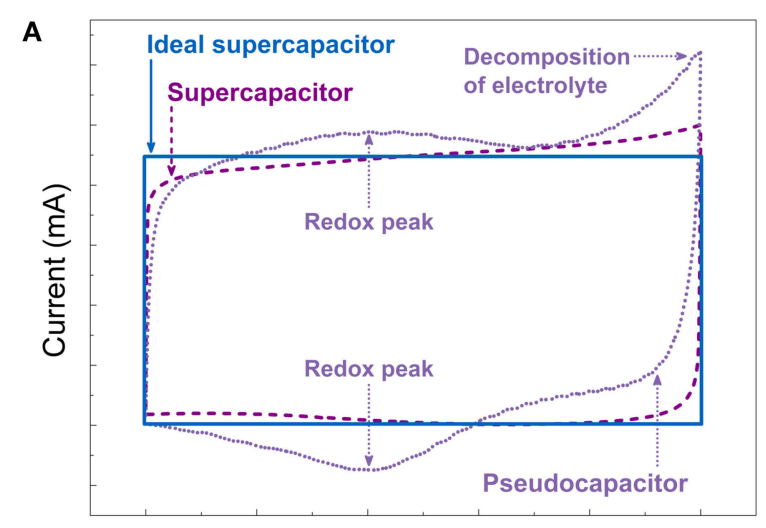

Potential (V)

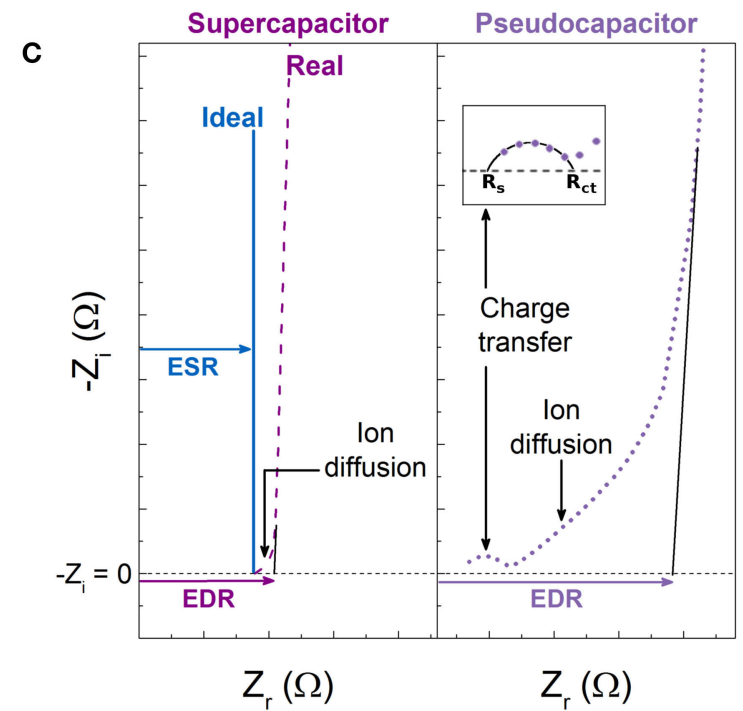

E

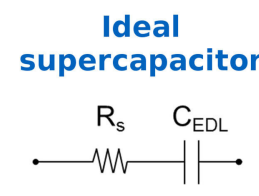

B

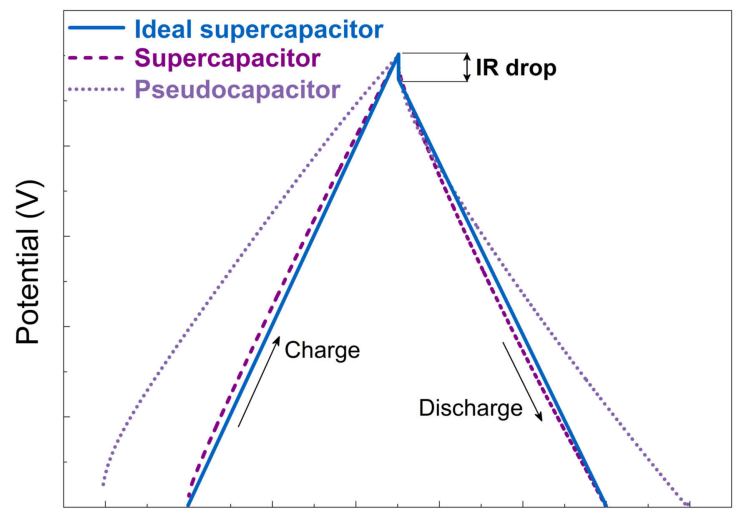

Time (s)

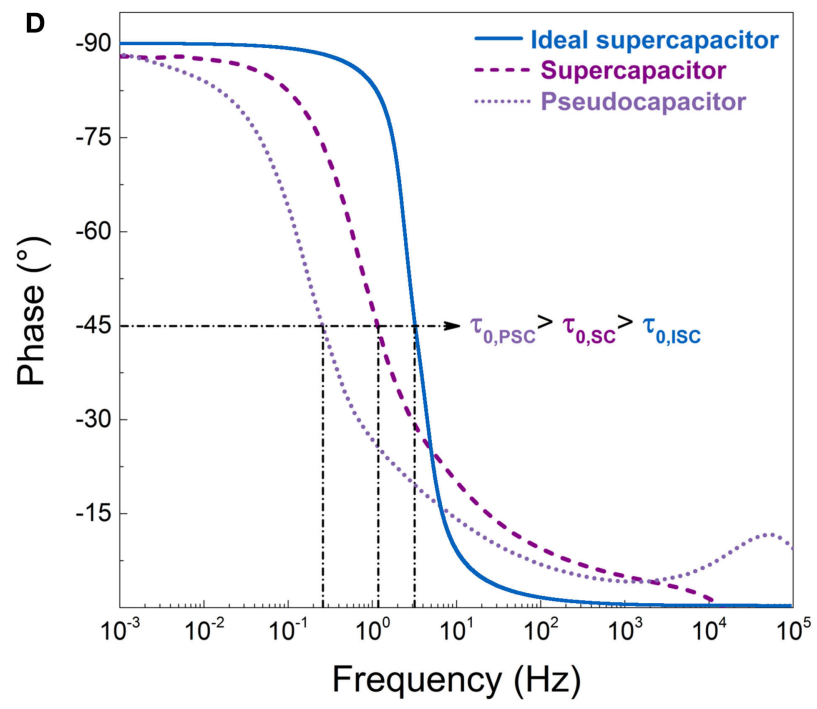

G

Supercapacitor

Pseudocapacitor

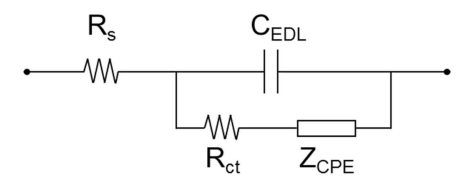

FIGURE 4 | Expected behavior of a supercapacitor (SC) and a pseudocapacitor (PSC) compared to that of an ideal SC during different electrochemical tests: (A) cyclic voltammetry, (B) galvanostatic charge-discharge, and (C,D) electrochemical impedance spectroscopy. Simplified equivalent circuits for: (E) ideal SC, (F) SC, and (G) PSC.

Data obtained from EIS measurements can also be represented in a Bode diagram, see Figure 4D, where the phase and/or modulus of the complex impedance are/is plotted as a function of frequency. Bode diagrams are useful tools for easily identifying the relaxation time constant, $\tau_{0}$, of the device, which is the inverse of the frequency at which the phase angle is $45^{\circ}$. This parameter is related to the power output of the SC. A low $\tau_{0}$ leads to a rapid charge-discharge resulting in a high power capability (Orazem and Tribollet, 2008; Inamuddin et al., 2018).

\section{ELECTROLYTES USED IN SCs}

The energy stored in a SC can be considerably increased by widening the potential window, see again Equation (3), which is essentially limited by the stability of the electrolyte. Increasing the potential beyond this limit causes the decomposition of the electrolyte, resulting in unwanted reactions that sharply increase the current, reduce the performance and can degrade the materials in the SC (Zhong et al., 2015). Even though the 
selection of the electrolyte is mainly defined by its stability, other properties such as conductivity, ion size and mobility, ionelectrode interaction or thermal stability must also be considered. Currently, aqueous and organic liquid electrolytes are the most widely used. Table 1 shows their general properties.

Aqueous electrolytes are perhaps the most used in academic research because they have a low cost, they are easy to handle, and they present high ionic conductivity and mobility leading to a low ESR (González et al., 2016). Among them, acidic, alkaline, or neutral solutions can be used (Zhong et al., 2015; Wang et al., 2016). Acidic and alkaline electrolytes are likely to provide pseudocapacitance contributions by reacting with oxygen or nitrogen surface functional groups present in carbon electrodes (Zhai et al., 2011; Salinas-Torres et al., 2019). The potential window of aqueous electrolytes is limited to $\sim 1.2 \mathrm{~V}$, beyond which water begins to decompose. Besides, they are not suitable for applications where the temperature is much lower than $0^{\circ} \mathrm{C}$ or much higher than $100^{\circ} \mathrm{C}$ (Zhong et al., 2015). Organic electrolytes predominate on the market because they offer the possibility of using larger potential windows. They consist of salts dissolved in organic solvents that can reach potential windows up to $3.5 \mathrm{~V}$ and operate at temperatures as low as $-40^{\circ} \mathrm{C}$ (Zhong et al., 2015). However, the larger ion size of typical organic electrolytes limits their mobility, so they have lower conductivities than those of aqueous electrolytes (Wang et al., 2016). In addition, organic electrolytes still face the problems related to their high toxicity, flammability and high costs due to the necessary purification processes and the controlled environment for the assembly of the SCs (Zhong et al., 2015).

\section{CARBON MATERIALS AS ELECTRODES FOR SUPERCAPACITORS}

The use of porous carbon materials as electrodes for SCs has increased over the years. Such materials indeed have high chemical and thermal stability, good conductivity, possibility of adjusting their textural properties, and industrial processes for electrode synthesis and production already established. In addition, carbon cloths or monoliths can be produced and used directly as electrodes, eliminating the need of binders to maintain their shape (Kötz and Carlen, 2000; Sevilla and Mokaya, 2014; Wang et al., 2016). From Equation (1), it can be seen that a material with a high surface area should result in a highcapacitance SC as long as this surface is accessible to electrolyte ions. The latter highlighted the importance of matching the size of the pores to the size of the electrolyte ions. Some studies had also reported that a hierarchical porous structure connecting micro-, meso- and macropores (pore width $w<2 \mathrm{~nm}, 2<$ $w<50 \mathrm{~nm}$, and $w>50 \mathrm{~nm}$, respectively) helps improve SC performances by providing interconnected channels that facilitate ion diffusion in the material (Frackowiak, 2007; Inagaki et al., 2010). Porous carbon materials are also of particular interest because the addition of specific functional groups to their surface results in higher capacitances due to improved conductivity and/or higher pseudocapacitance contributions (Paraknowitsch and Thomas, 2013).

Efforts to increase the energy density in carbon-based SCs focus on these three aspects: development of porous materials with high surface area, tailoring of pore size, and modification of surface chemistry. The following subsections deal with the description of the synthesis processes and the resultant properties of different porous carbon materials for their application as electrodes for SCs.

\section{Activated Carbons}

Most electrodes in SCs are based on powders of activated carbon (AC). There is a predominant use of biomass as raw material for commercial and laboratory production of ACs, given that agricultural, forestry, municipal and animal byproducts are abundant and inexpensive. Coal or coke can also be used to produce ACs (Zhao et al., 2012; Tellez-Juárez et al., 2014; González-García, 2018). Figure 5 shows schematically the production process by physical or chemical activation methods.

Physical activation is based on the partial and controlled gasification of a carbonaceous material in an atmosphere containing an oxidizing gas, such as steam, $\mathrm{CO}_{2}$, air or their mixes, at temperatures ranging from 350 to $1,000^{\circ} \mathrm{C}$. Before physical activation, pyrolysis at temperatures between 400 and $900^{\circ} \mathrm{C}$ or hydrothermal carbonization (HTC) at lower temperatures $\left(130\right.$ to $250^{\circ} \mathrm{C}$ ) is generally required (Cha et al., 2016; Selmi et al., 2018; Mbarki et al., 2019). The final textural and chemical properties of the ACs depend largely on the activation time and temperature. When the same activating agent is used, a higher degree of activation leads to a higher development of porosity and a broadening of the pore size distribution (PSD). Physical activation normally produces materials with surface areas up to $\sim 1,800 \mathrm{~m}^{2} \mathrm{~g}^{-1}$ and maximum pore volumes of $\sim 0.9$ $\mathrm{cm}^{3} \mathrm{~g}^{-1}$ (Sevilla and Mokaya, 2014; González-García, 2018).

Chemical activation is carried out using compounds such as $\mathrm{KOH}, \mathrm{NaOH}, \mathrm{H}_{3} \mathrm{PO}_{4}$, or $\mathrm{ZnCl}_{2}$, among others. The precursor is mixed with the activating agent and then subjected to pyrolysis at temperatures between 400 and $900^{\circ} \mathrm{C}$. Finally, the AC needs to be washed to remove the residues generated during the activation process. Direct chemical activation of biomass is preferred when using $\mathrm{ZnCl}_{2}$ or $\mathrm{H}_{3} \mathrm{PO}_{4}$ because they dehydrate biomass, which reduces the quantity of volatile matter released during pyrolysis, thus increasing the carbon yield (Fierro et al., 2005, 2010). KOH or $\mathrm{NaOH}$ can be used to activate either untreated biomass or char (Fierro et al., 2007; Basta et al., 2009; Acosta et al., 2018). Higher amounts of activating agent result in more developed porosity. $\mathrm{H}_{3} \mathrm{PO}_{4}$ and $\mathrm{ZnCl}_{2}$ generate micropores and small mesopores and lead to ACs with surface areas lower than $2,000 \mathrm{~m}^{2} \mathrm{~g}^{-1}$. On the other hand, $\mathrm{KOH}$ can produce higher surface areas, wider PSD and pore volumes of $2.7 \mathrm{~cm}^{3} \mathrm{~g}^{-1}$ or more. Such further development of porosity is probably due to the generation of $\mathrm{CO}_{2}$ as a by-product of the reaction between the carbon and $\mathrm{KOH}$ (Sevilla and Mokaya, 2014). The use of less corrosive or harmless salts for the activation of biomass and biomass-derived precursors, such as potassium carbonate, potassium bicarbonate, potassium oxalate, or sodium thiosulfate, has been explored (Fuertes et al., 2018; Díez et al., 2019). Materials with high surface 
TABLE 1 | Properties of aqueous and organic electrolytes often used in SCs (Lide, 2004; Conte, 2010; Zhong et al., 2015; Lu et al., 2018).

\begin{tabular}{|c|c|c|c|c|c|c|}
\hline \multirow[t]{2}{*}{ Type } & \multirow[t]{2}{*}{ Electrolyte } & \multirow{2}{*}{$\begin{array}{l}\text { Potential window } \\
\text { [V] }\end{array}$} & \multicolumn{2}{|c|}{ Solvated ion size [nm] } & \multirow{2}{*}{$\begin{array}{l}\text { Conductivity }\left[\mathrm{S} \mathrm{cm}^{-1}\right] \\
\text { (concentration) }\end{array}$} & \multirow{2}{*}{$\begin{array}{l}\text { Freezing and boiling point } \\
{\left[{ }^{\circ} \mathrm{C}\right]}\end{array}$} \\
\hline & & & Cation & Anion & & \\
\hline \multirow[t]{3}{*}{ Aqueous } & $\mathrm{H}_{2} \mathrm{SO}_{4}$ & $0.7-1.0$ & 0.28 & 0.38 & $0.8(1 \mathrm{M})$ & \\
\hline & $\mathrm{KOH}$ & $0.9-1.0$ & 0.33 & 0.30 & $0.6(6 \mathrm{M})$ & \\
\hline & $\mathrm{Na}_{2} \mathrm{SO}_{4}$ & $1-1.8$ & 0.36 & 0.38 & $0.01(0.1 \mathrm{M})$ & \\
\hline \multirow[t]{2}{*}{ Organic } & $\mathrm{TEABF}_{4} / \mathrm{ACN}$ & $2.5-2.8$ & 1.3 & 1.16 & $0.05(0.65 \mathrm{M})$ & -49 to $+82^{\circ} \mathrm{C}$ \\
\hline & $\mathrm{TEABF}_{4} / \mathrm{PC}$ & $2.5-3.5$ & 1.35 & 1.4 & $0.01(0.65 \mathrm{M})$ & -49 to $+242^{\circ} \mathrm{C}$ \\
\hline
\end{tabular}

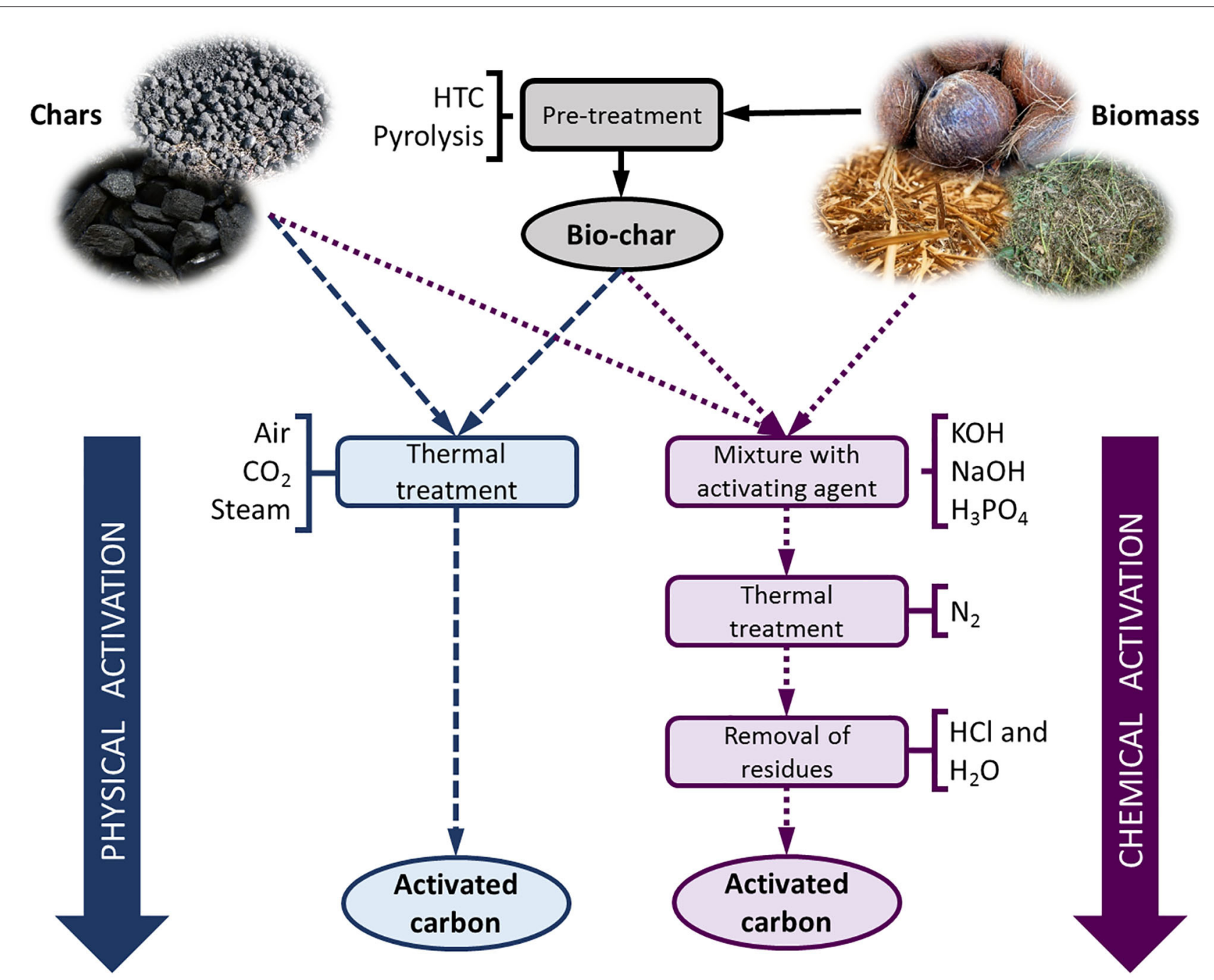

FIGURE 5 | Schematic production process of activated carbons, from biomass and char, by physical or chemical activation.

areas and pore volumes, up to $2,750 \mathrm{~m}^{2} \mathrm{~g}^{-1}$ and $2.4 \mathrm{~cm}^{3} \mathrm{~g}^{-1}$, respectively, have been reported.

The advanced materials described in the following sections can also be activated to improve their textural properties. However, here they differ from ACs materials since their physicochemical properties are mainly related to synthesis rather than the activation process.

\section{Carbide-Derived Carbons and Zeolite-Templated Carbons}

In order to have a higher control of the microporosity, different methods for the synthesis of carbon materials from carbides or zeolites have been developed (Lee et al., 2006; Inagaki et al., 2010). High-temperature chlorination $\left(400-1,200^{\circ} \mathrm{C}\right)$ of silicon or titanium carbide is used to remove metal atoms and obtain 
microporous materials. Such carbide-derived carbons (CDCs) exhibit surface areas between 1,000 and $2,000 \mathrm{~m}^{2} \mathrm{~g}^{-1}$ and a uniform and disordered pore structure. The pore size can be adjusted from 0.6 to $1.1 \mathrm{~nm}$ by changing the carbide precursor, the chlorination or the heat-treatment temperature (Zhai et al., 2011). On the other hand, zeolite-templated carbons (ZTCs) are produced by incorporating a carbon precursor, e.g., phenol, inside the zeolite structure and carbonizing it. After template removal, a structure with the same periodicity as the original zeolite is obtained. ZTCs reach surface areas higher than $2,000 \mathrm{~m}^{2}$ $\mathrm{g}^{-1}$ and present pore volumes of $1 \mathrm{~cm}^{3} \mathrm{~g}^{-1}$ or more (Lee et al., 2006; Mostazo-López et al., 2018). For both CDCs and ZTCs, the pore structure consists only of micropores with a minor presence of mesopores. Activation of these materials introduces mesoporosity and broadens the micropores, which can improve ion diffusion in the porous materials when used as electrodes for SCs (Mostazo-López et al., 2018).

\section{Carbon Gels}

Pyrolysis of organic gels prepared from resorcinol-formaldehyde resins has been used to produce carbon gels (CGs) with surface areas between $\sim 500$ and $\sim 1,000 \mathrm{~m}^{2} \mathrm{~g}^{-1}$ and presenting a high fraction of mesopores. In general, the production of CGs involves five steps: polymerization of the precursor to form an organic gel, aging, solvent exchange, drying, and carbonization (Grishechko et al., 2016; Ciszewski et al., 2019). CGs are classified, according to the drying technique, as aerogels, xerogels, or cryogels whether supercritical, subcritical or freeze drying, respectively, has been used (Braghiroli et al., 2019). Each step of the synthesis process has an impact on the porous texture of the resultant CGs. On the one hand, the precursor to catalyst ratio and the $\mathrm{pH}$ of the solution modify the polymerization process and lead to materials of different textures (Szczurek et al., 2011a,b). On the other hand, controlling the drying process is of paramount importance to avoid the formation of cracks or the shrinkage of the material (Feinle et al., 2016). For SC applications, it has been found that the mainly mesoporous structure of CGs limits the effectiveness of the EDL mechanism and that activation generally allows developing a narrow porosity not accessible to ions, leading to a moderate improvement in electrochemical performance compared to the increase in surface area (Pandolfo and Hollenkamp, 2006; Zhang and Zhao, 2009).

\section{Nanostructured Carbons}

Carbon nanotubes, nanofibers and nanospheres (CNTs, CNFs, and CNSs, respectively) have also been used as electrodes of SCs. Although the surface area of CNFs and CNTs is moderate, $\sim 400$ $\mathrm{m}^{2} \mathrm{~g}^{-1}$, they have been considered for SCs electrodes given that their entanglement results in multiple charge storage sites $(\mathrm{Gu}$ and Yushin, 2014), as seen in Figures 6A,B. CNFs and CNTs obtained by electrospinning techniques or by direct growth on conductive substrates allow flexible mats to be produced, which can be directly used as electrodes in SCs (Ra et al., 2009; Kim et al., 2012; Gu and Yushin, 2014). Likewise, aligned CNFs and CNTs can be grown directly on current collectors (Kim et al., 2003; Gao et al., 2008; Zheng et al., 2017). SCs with electrodes based on aligned CNFs or CNTs could exhibit improved performance at high charging rates due to a shortening of the conductive path for the charges (Inagaki et al., 2010). However, the performance of CNTs as electrodes in SCs is strongly affected by the presence of impurities (Frackowiak and Beguin, 2001). In addition, activation is generally needed to create micropores on the surface of CNFs and increase the number of charge storage sites (Inagaki et al., 2010; Gu and Yushin, 2014). On the other hand, it is nowadays possible to synthesize a wide variety of CNSs, whether solid, hollow, or onion-like, among others, and with micro-, meso-, and/or macropores, see examples in Figures 6C,D. The surface areas vary from low, $<100 \mathrm{~m}^{2} \mathrm{~g}^{-1}$, to high, $\sim 2,000 \mathrm{~m}^{2} \mathrm{~g}^{-1}$, and the sphere sizes range from tens of $\mathrm{nm}$ to hundreds of $\mu \mathrm{m}$ (Liu et al., 2015). The strategies for synthesizing CNSs include different types of hard- and soft-template techniques, emulsion polymerization, self-assembly or the Stöber method (Liu et al., 2015; Li et al., 2016). Typically, petrochemical precursors are used to produce CNSs, but HTC processes have successfully used glucose, sucrose, cellulose or tannin to obtain CNSs (Braghiroli et al., 2015b; Liu et al., 2015; Li et al., 2016). Uniform CNSs can be packed in high-density electrodes, maintaining the electrolyte accessibility thanks to voids between the particles. Therefore, this type of electrode allows a large amount of energy to be stored in small-volume devices (Ferrero et al., 2015). Despite the advantages of CNSs, the multi-step synthesis process, the use of hazardous substances to etch the hard templates and the low yields associated with soft-template methods limit their extensive use for widespread production (Liu et al., 2015; Li et al., 2016).

\section{Ordered Mesoporous Carbons}

In order to develop materials with a hierarchical pore structure, many studies have been devoted to the design and engineering of ordered mesoporous carbons (OMCs) with tuned morphology and porosity. If necessary, an activation process is carried out to increase their surface area. In this way, OMCs have the advantage of having a hierarchical pore structure to provide interconnected channels for the diffusion of electroactive species, thus making them suitable for application in SCs (González et al., 2016; Lim et al., 2016; Wang et al., 2016). OMCs can be synthesized by hard- or soft-template methods. Both are shown in Figure 7A, and further details are given below.

The hard-template method uses an inorganic material that is filled with the carbon precursor. After polymerization, the composite is subjected to carbonization, and the template is then removed. As a result, the OMC obtained is an inverse replica of the template (Lee et al., 2006). Mesoporous silicas are the most used in this kind of techniques, but having to synthesize such templates before sacrificing them makes the procedure expensive, polluting and time-consuming. Thus, efforts to synthesize OMCs from biosourced templates have been made to take advantage of naturally ordered and hierarchical structures found in diatomaceous earth, pollen grains or leaves, among others (Liu et al., 2012; Xia et al., 2012; Gao et al., 2017). However, the procedure still involves the use of hazardous substances to crosslink the precursor and/or to etch the template.

In the soft-template method, an amphiphilic surfactant is used in solution to form micelles. The hydrophilic part of the micelle interacts with the carbon precursor that 

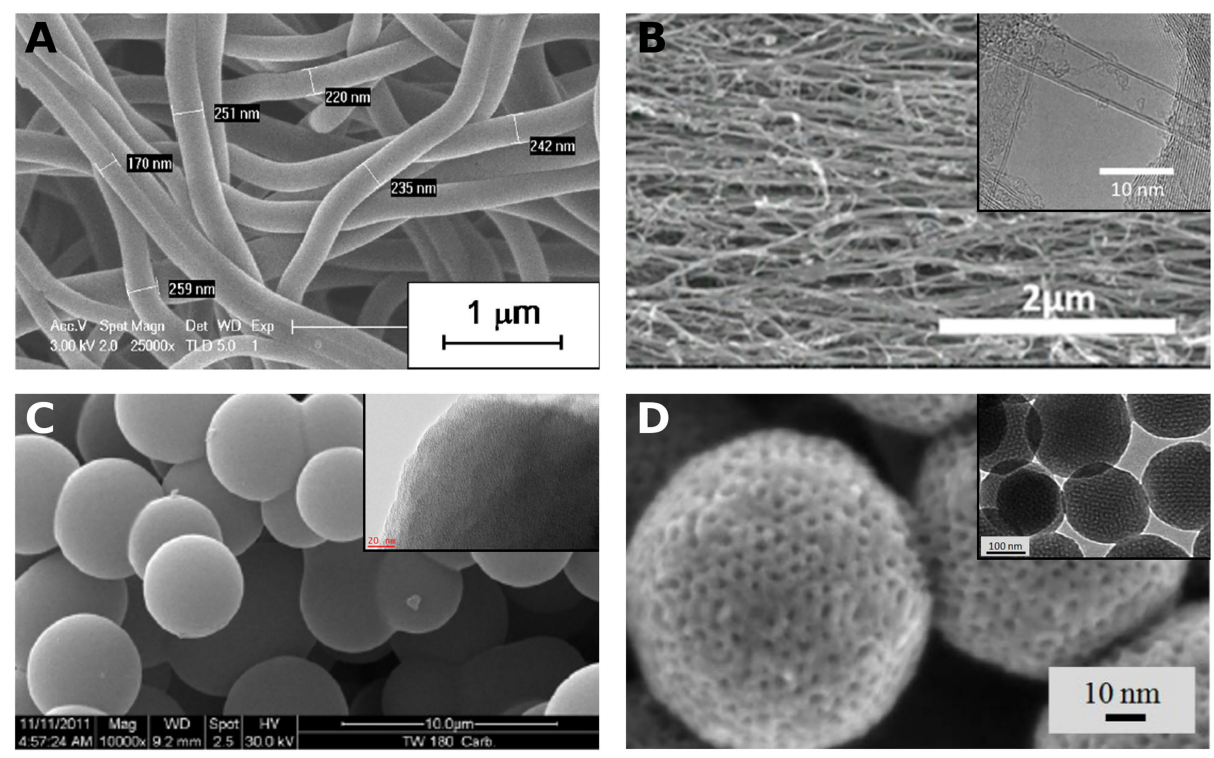

FIGURE 6 | (A) Electrospun CNFs from Kraft lignin (Adapted from Vivo-Vilches et al., 2019). SEM (and TEM in the insets) images of: (B) commercial CNTs-Poly(dicyclopentadiene) composite yarn (Adapted from Xin et al., 2020); (C) solid CNSs derived from tannin (Adapted with permission of Elsevier, from Braghiroli et al., 2012; permission conveyed through Copyright Clearance Center, Inc.); (D) ordered mesoporous CNSs from phenol (Adapted from Chang et al., 2015).

polymerizes around the surfactant. Then, the carbonization process eliminates the surfactant, revealing the mesoporosity at the same time (Libbrecht et al., 2017). Different combinations of commercially available block copolymers such as Pluronic ${ }^{\circledR}$ or Vorasurf ${ }^{\circledR}$ as surfactants and phenol, phloroglucinol, resorcinol, or tannin as carbon precursors have been used to successfully synthesize OMCs by soft-template methods (Meng et al., 2006; Wickramaratne and Jaroniec, 2013; Braghiroli et al., 2016; Libbrecht et al., 2017).

In both hard- and soft-templating, the mesopore order is determined by the characteristics of the template. Given the diversity of templates and precursors available, OMCs have surface areas from $\sim 500$ to more than 2,000 $\mathrm{m}^{2} \mathrm{~g}^{-1}$, and various PSDs in the micro-mesopore range. Thus, the versatility of OMCs turns them into an interesting choice of materials to be used as SC electrodes. Figures 7B-E shows examples of OMCs with different pore structures.

\section{Doped Materials}

A potential route to increase the energy stored in SCs is heteroatom doping of carbon materials, which promotes fast Faradaic reactions and enhances their performances via pseudocapacitance contributions. All the materials described in the previous sections (Sections Activated Carbons to Ordered Mesoporous Carbons) are subject to surface modification. Although doping with boron, sulfur or phosphorus has been investigated (Paraknowitsch and Thomas, 2013; Bairi et al., 2015; Chen et al., 2015; Elmouwahidi et al., 2018), the introduction of heteroatoms such as oxygen $(\mathrm{O})$ or nitrogen $(\mathrm{N})$ is recurrent because it is relatively easy to perform. In consequence, $\mathrm{O}$ - and $\mathrm{N}$-doping have been studied in depth.
Figure 8A displays the most common $\mathrm{O}$ - and $\mathrm{N}$ - surface functional groups associated with improving the performance of carbon-based SCs.

Oxygen functionalities are normally found in porous carbon materials. To further dope the materials with oxygen, activation and/or oxidation treatments in $\mathrm{HNO}_{3}, \mathrm{H}_{2} \mathrm{SO}_{4}$, or using $\mathrm{O}_{2}$ can be carried out; electro-oxidation using different basic, neutral or acidic electrolytes has also been explored (Inagaki et al., 2010; Berenguer et al., 2013; Sevilla and Mokaya, 2014). The final amount and the type of functionality on the carbon surface depend on the precursor and the synthesis method. Some of the proposed redox reactions involving oxygen surface groups are shown in Figures 8B-F (Chen et al., 2012; Sánchez-Sánchez et al., 2016). In acidic electrolytes, it has been reported that quinone functionalities have the largest contribution to capacitance, Figure 8B (Hulicova-Jurcakova et al., 2009). Even though the carboxylic groups could increase the capacitance through the generation of charges, see Figure $8 \mathrm{E}$, their high polarity could also produce resistance to ion diffusion, reducing the performance (Sevilla and Mokaya, 2014). Nevertheless, carboxylic and phenolic groups are also likely to react in alkaline solutions, see Figures 8D,F, with a positive impact on the SC performance (Zuliani et al., 2018).

$\mathrm{N}$-doping by post-treatment is carried out by HTC and/or annealing of a mixture of the carbon material with a nitrogen precursor, e.g., ammonia or urea (Inagaki et al., 2018). Ndoping can also be performed in situ by direct pyrolysis of a nitrogen-rich carbon precursor (Raymundo-Piñero et al., 2009) or by multi-step methods to produce CNSs (Braghiroli et al., 2015b; Ferrero et al., 2015; Wang et al., 2018), CNTs (Ayala et al., 2010), or OMCs (Sánchez-Sánchez et al., 2016; Moussa 

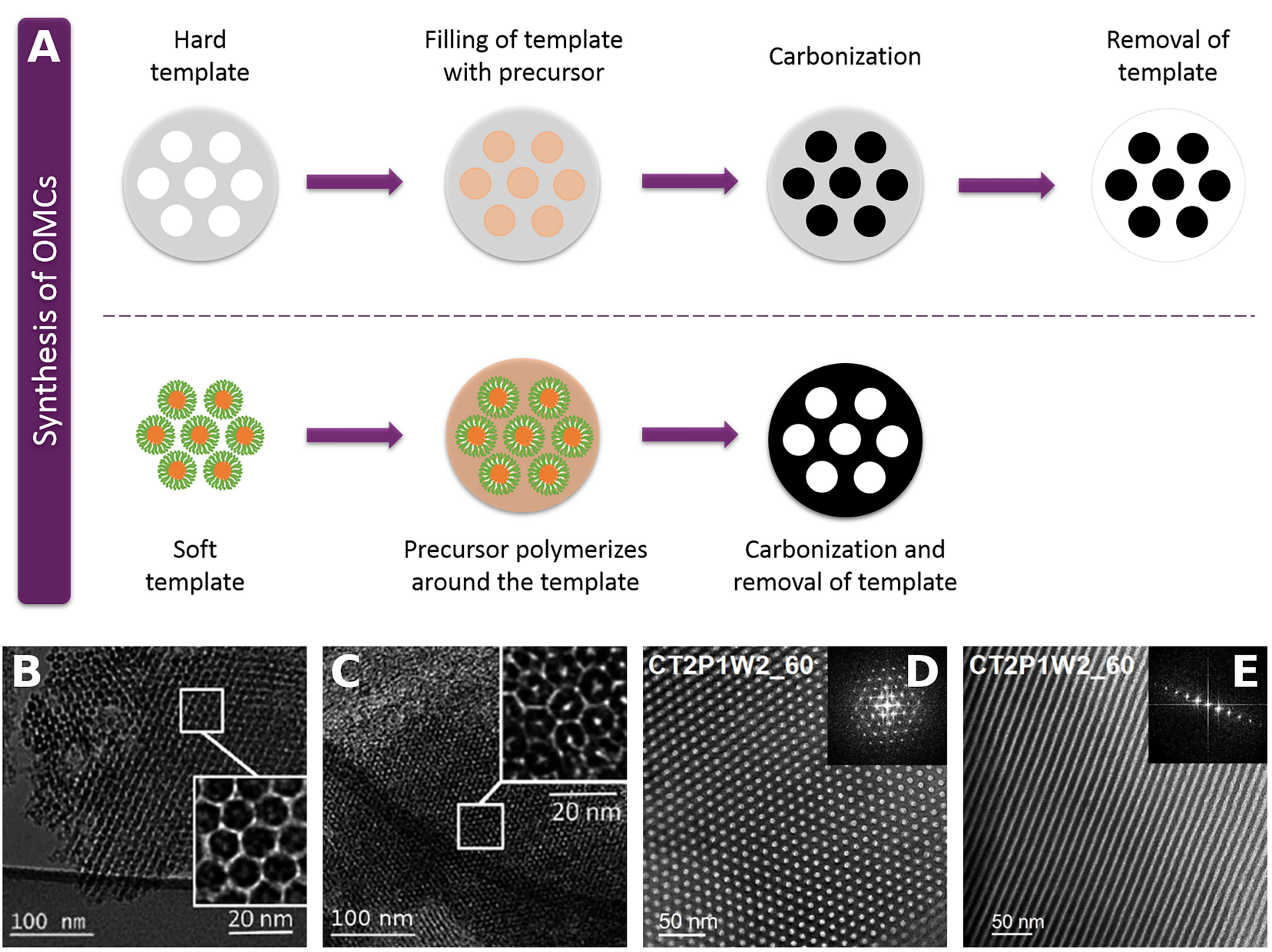

FIGURE 7 | (A) Schematic synthesis of OMCs by hard and soft template methods. (B,C) Hard-templated OMCs using SBA-15 as template and aminobenzoic acid as precursor (Adapted from Sánchez-Sánchez et al., 2016 by permission of The Royal Society of Chemistry). (D,E) Soft-templated OMCs using Pluronic ${ }^{\circledR}$ F127 as template and mimosa tannin as precursor (Adapted from Castro-Gutiérrez et al., 2018 by permission of The Royal Society of Chemistry).

et al., 2018). Isolating the contribution of $\mathrm{N}$-functionalities to the SCs performance is a difficult task since nitrogen is always present with oxygen and can lead to modifications of textural properties. However, a correlation between the SCs performance and the amount and type of nitrogen functionalities has been reported (Frackowiak et al., 2006; Hulicova-Jurcakova et al., 2009; Braghiroli et al., 2015c). N-doped materials can reach high values of capacitance even if their surface areas are relatively low. This have been attributed to pseudocapacitance contributions but also to improved wettability and conductivity of the materials (Inagaki et al., 2010). Most studies agree that the major contribution to pseudocapacitance comes from the pyridinic, pyrrolic, and pyridine groups, see Figures $\mathbf{8 G}-\mathbf{K}$ (Deng et al., 2016). However, some studies have suggested that quaternary groups interact with protons or anions in $\mathrm{H}_{2} \mathrm{SO}_{4}$ or $\mathrm{KOH}$ electrolytes, respectively, and could promote electron transfer through the carbon structure (Deng et al., 2016).

\section{TRANSITION TO BIOSOURCED PRECURSORS OF POROUS CARBON MATERIALS}

Apart from ACs, which are often produced on an industrial scale from biomass materials, most of the synthesis methods described in section Carbon Materials as Electrodes for Supercapacitors use precursors of petrochemical origin. For example, resorcinol or phenol crosslinked with formaldehyde are widely used to synthesize different types of OMCs (Zhu et al., 2016; Lu et al., 2018; Li et al., 2019). In an effort to research more environmentally friendly technologies and methods, biosourced substitutes for ordinary carbon precursors have been explored. A salt template-assisted, chemical activation process was applied by subjecting gelatin, sucrose, glucose or tannic acid (TA) mixed with $\mathrm{KCl}$ and $\mathrm{Na}_{2} \mathrm{~S}_{2} \mathrm{O}_{3}$ to carbonization (Fuertes et al., 2018; Sevilla et al., 2019). The resultant micro-mesoporous carbon materials had high surface areas in the range of 1,900-2,720 


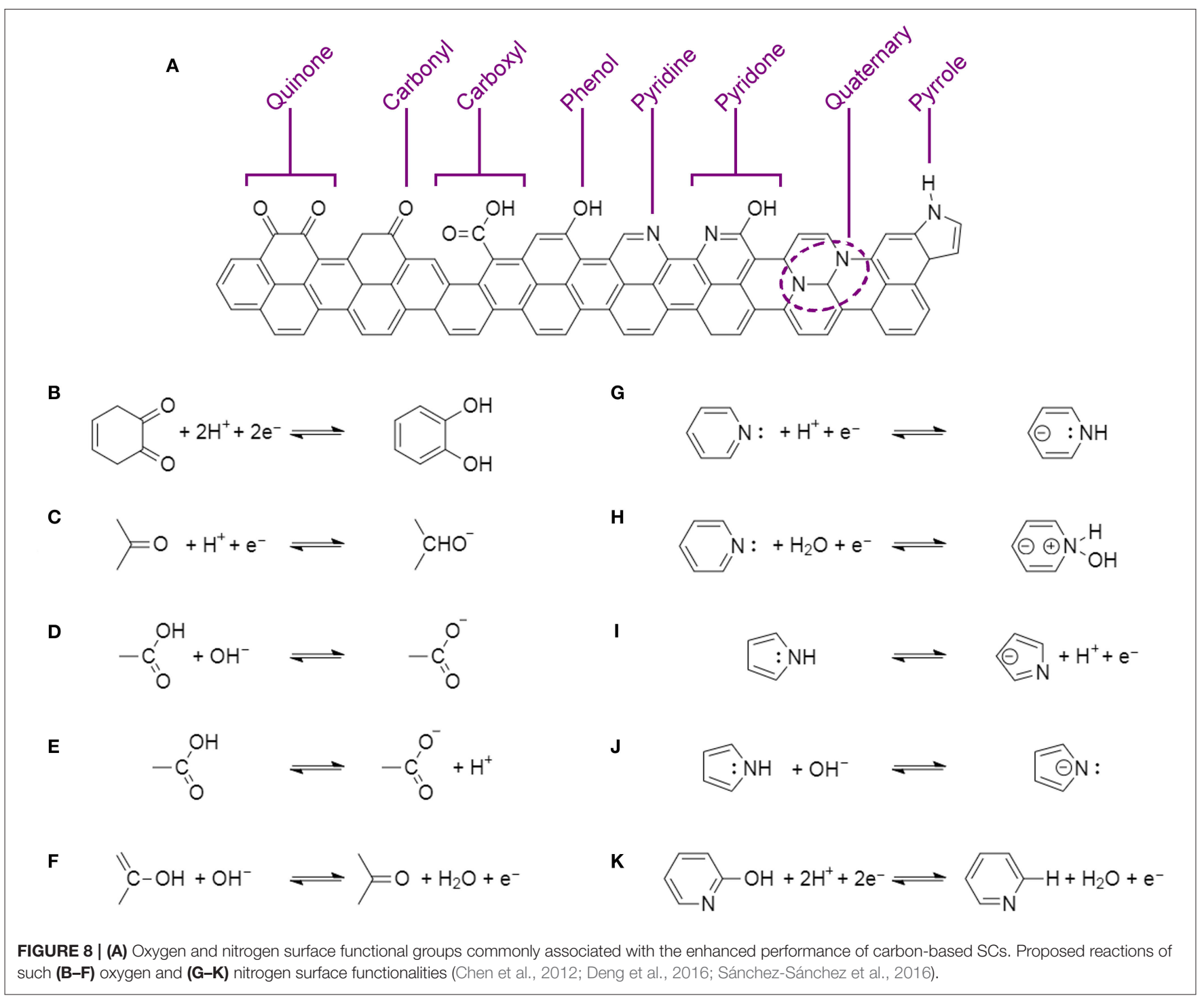

$\mathrm{m}^{2} \mathrm{~g}^{-1}$. TA has also been used to produce micro-mesoporous CNSs by direct heat-treatment of the precursor mixed with urea and an eutectic salt $\left(\mathrm{NaCl} / \mathrm{ZnCl}_{2}\right)$ (Tiruye et al., 2017) and to synthesize CNFs by carbonization of a glass fabric previously impregnated with TA (Hu et al., 2020). Hard-templating of sucrose with cubic and 2D hexagonal silica templates produced highly porous materials with surface areas as high as 2,000 $\mathrm{m}^{2} \mathrm{~g}^{-1}$ (Vix-Guterl et al., 2005). Also based on the use of silica templates, OMCs with surface areas higher than $900 \mathrm{~m}^{2}$ $\mathrm{g}^{-1}$ were synthesized from different types of biomass-derived phenols such as phloroglucinol, gallic acid, catechin, and mimosa tannin (Sanchez-Sanchez et al., 2017a). By soft-template routes, it has been reported that $2 \mathrm{D}$ hexagonal OMCs with surface areas $\sim 700 \mathrm{~m}^{2} \mathrm{~g}^{-1}$ were obtained by hydrothermal treatment of $\beta$-cyclodextrin, extracted from starch, mixed with Pluronic ${ }^{\circledR}$ F127 and P123 (Feng et al., 2014) or by evaporation-induced self-assembly (EISA) using a mixture of lignin, phloroglucinol, glyoxal, and Pluronic ${ }^{\circledR}$ F127 (Herou et al., 2019). Besides, a phase-separation method was able to produce $\mathrm{N}$-doped $2 \mathrm{D}$ hexagonal OMC with a moderate area of $523 \mathrm{~m}^{2} \mathrm{~g}^{-1}$ from phloroglucinol, glyoxylic acid, and guanine (Moussa et al., 2018).

\section{TANNINS AS CARBON PRECURSOR}

Tannins are polyphenolic substances present in many plants and trees. They have been used in the leather manufacturing process since the Middle Ages (SilvaTeam, 2018; CAPPEQ, 2019b). Their industrial production increased in the 1970s thanks to the development of tannin adhesives for wood (Fierro et al., 2018). Nowadays, tannins are used not only for tanning leather (hence their name), but also as wine additives, food supplements and cosmetic ingredients (CAPPEQ, 2019c). Although there are several methods for extracting tannins, the solid-liquid method is the one traditionally used on an industrial scale due to its simplicity, efficiency and low cost (de Hoyos-Martínez et al., 2019). The solid-liquid extraction method involves the 
dissolution of tannins in water at moderate temperature (60$70^{\circ} \mathrm{C}$ ), after which the solution is concentrated and spray-dried to obtain a red-brown powder (CAPPEQ, 2019a; de HoyosMartínez et al., 2019). The chemical composition of the final powder strongly depends on the plant species and the part of the plant from which the tannin has been extracted. However, the similarities in their compositions allow them to be classified into two broad categories, namely hydrolysable or condensed (Tondi and Petutschnigg, 2015; de Hoyos-Martínez et al., 2019). In particular, condensed tannins are of primary interest in the synthesis of carbon materials as they contain more than $70-80 \%$ of polyflavonoids. Their aromatic rings with hydroxyl groups give polyflavonoids a reactivity similar to that of phenolic molecules of petrochemical origin such as phenol or resorcinol (Pizzi, 1982; Fierro et al., 2018), as well as a high carbon yield upon pyrolysis, $\sim 50 \%$. More details on the properties of condensed tannins are given in the next subsection.

\section{Condensed Tannins}

The polyflavonoids of condensed tannins are composed of flavan3-ol moieties made up of two phenolic rings (A and $\mathrm{B}$ ) linked by a heterocyclic ring. Figure 9 shows the main four types of flavonoid molecules of condensed tannins as well as with the type of trees in which they are found. Thus, mimosa (Acacia mearnsii), quebracho (Schinopsis balansae and Schinopsis lorentzii), and maritime pine (Pinus pinaster) are the most used species for the extraction of condensed tannins, representing $90 \%$ of the world's production (Fierro et al., 2018; Shirmohammadli et al., 2018). The reactivity of the flavonoid units depends on the position of the $-\mathrm{OH}$ groups and the available reaction sites. In this sense, it has been shown that the A-ring is more reactive than the B-ring (Pizzi, 1982). Indeed, tannins can naturally autocondense by linking the units at positions 4,6 for profisetinidin and prorobinetinidin or 4,8 for procyanidin and prodelphinidin (see again Figure 9), producing oligomers of up to 10 or 11 units (Haslam, 2007). The ability of condensed tannins to autocondense and react with aldehydes to form phenolic resins makes them an attractive alternative to produce high addedvalue materials.

In addition to their good chemical reactivity, tannins have the advantage of being non-toxic in the event of exposure to low amounts, and high doses can only cause irritation or have anti-nutritional effects (Schlienger et al., 2012). Compared to the toxicity and hazards of substances like resorcinol, phenol or formaldehyde, as shown in Table 2, tannins should be considered as excellent ecological and non-toxic alternative precursor to produce porous carbons.

\section{Synthesis of Porous Carbons}

Condensed tannins have been used to produce a wide variety of high added-value materials. The tannin-derived products can be converted into carbon by high-temperature treatment. The resulting materials are glass-like due to the non-graphitizing nature of the precursor, and present isotropic properties and good electrical conductivity. As for petrochemical precursors, the synthesis of porous materials from tannin usually requires the preparation of a resin by crosslinking with formaldehyde, hexamine, or glutaraldehyde, among other possible aldehydes. Thus, different materials have been synthesized such as foams (Tondi et al., 2009; Lacoste et al., 2013; Jana et al., 2014; Szczurek et al., 2014; Delgado-Sánchez et al., 2018), gels (Szczurek et al., 2011a,b; Amaral-Labat et al., 2013; Braghiroli et al., 2019), microspheres (Grishechko et al., 2016), or polyHIPEs (Szczurek et al., 2013). Furthermore, tannin autocondensation reactions enable its polymerization without having to use crosslinkers, opening the way for the production of OMCs by self-assembly techniques (Schlienger et al., 2012; Braghiroli et al., 2016). The following section describes some of the methods used to obtain micro-mesoporous carbon materials from tannin, as well as their performance when used as electrodes for SCs, they are summarized in Table 3.

\section{Sol-Gel}

CGs were produced from mimosa tannin and formaldehyde (TF) organic cryogels (Amaral-Labat et al., 2012). The $\mathrm{pH}$ of mimosa tannin solutions was adjusted with either acetic acid or $\mathrm{NaOH}$ diluted in water to obtain a $\mathrm{pH}$ ranging from 3.3 to 7.3. Such solutions were placed in an oven at $85^{\circ} \mathrm{C}$ for 5 days, in which gelation and aging took place. After exchanging water for tertbutanol, the gels were freeze-dried to obtain TF cryogels. Finally, CGs were produced by carbonization of TF cryogels at $900^{\circ} \mathrm{C}$. Surface areas from 399 to $1,420 \mathrm{~m}^{2} \mathrm{~g}^{-1}$ were obtained, with minimum values found for $\mathrm{pH} 4.3$ and 5.3 and attributed to pore collapse during carbonization. The highest surface areas were found for $\mathrm{pH}>6$. This unusual development of surface area was ascribed to the presence of $\mathrm{NaOH}$, which could act as an activating agent during the carbonization process. The textural characterization revealed that the CGs were mainly microand macroporous materials, with an unusually low amount of mesopores.

In order to test their electrochemical performance, the CGs were ground to prepare pellets by mixing the corresponding sample, carbon black and PVDF (75:5:20 wt. \%), and then symmetrical SCs were assembled and tested in a T-type cell. CV tests were carried out from 2 to $50 \mathrm{mV} \mathrm{s}^{-1}$ using $4 \mathrm{M} \mathrm{H}_{2} \mathrm{SO}_{4}$ as electrolyte in a potential window of $1 \mathrm{~V}$. The values of $C_{e}$ of the CGs at $2 \mathrm{mV} \mathrm{s}^{-1}$ ranged from 30 to $109 \mathrm{~F} \mathrm{~g}^{-1}$, similar to the values found for more expensive carbon aerogels. As expected, the best performance was observed for the materials with the highest surface area. However, as the scan rate increased, the CV curves became narrower and lost their quasi-rectangular shapes, indicating a loss of SC behavior and resulting in a decrease of $C_{e}$. It was concluded that, although these CGs were highly porous, the values of capacitance were generally lower than expected due to the large amount of macropores that do not account for the capacitance. Besides, the sharp drop in $C_{e}$ with the increase in scan rate was related to the absence of mesopores to facilitate the diffusion of electrolyte ions in the micropores.

\section{Hydrothermal Carbonization}

Hydrothermal treatments of aqueous solutions of tannins take advantage of their autocondensation at very acidic or basic $\mathrm{pH}$. By varying $\mathrm{pH}$, tannin concentration and temperature, it is possible to obtain gels or spheres. Besides, it is possible to perform 


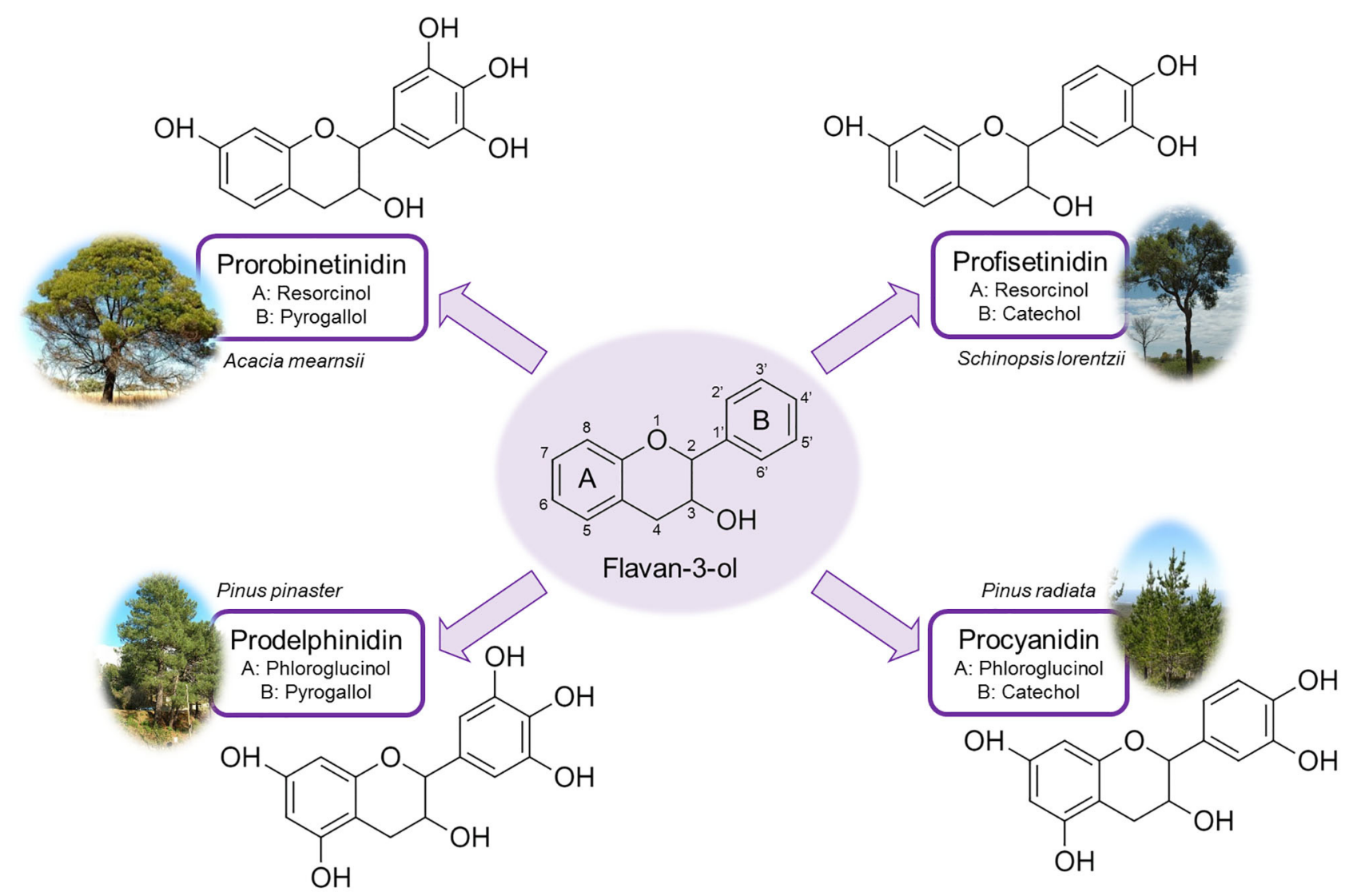

FIGURE 9 | Main flavonoid units of condensed tannins, along with the plant commonly used for their extraction (Fierro et al., 2018; Shirmohammadli et al., 2018).

$\mathrm{N}$-doping in situ by using ammonia solutions instead of water during the HTC process. Several examples of the electrochemical performances of carbonized, tannin-derived, HTC materials are described below.

$\mathrm{N}$-doped materials were produced by HTC of mimosa tannin (Braghiroli et al., 2015a,b). Two functionalization routes were followed: (i) dissolution of tannin in an aqueous ammonia solution, evaporation at room temperature, then dissolution of the solid residue in water solution followed by HTC; and (ii) dissolution of tannin in an aqueous ammonia solution followed by HTC. The former resultant material was called EAT (for "evaporated aminated tannin"), and the latter was called AT (for “aminated tannin”). A reference material, prepared by direct HTC of tannin in water, called T, was also synthesized. HTC was carried out at temperatures ranging from 180 to $220^{\circ} \mathrm{C}$ for $24 \mathrm{~h}$, and the recovered materials were carbonized at $900^{\circ} \mathrm{C}$. The morphology radically changed from CNSs for the reference materials to CG structure for the EAT-materials, while the carbon obtained by the AT-route presented a mixed morphology, see Figures 10A-C. The carbon materials exhibited surface areas between 113 and $684 \mathrm{~m}^{2} \mathrm{~g}^{-1}$. AT- and T-materials had a high proportion of ultramicropores (pores of width $<0.7 \mathrm{~nm}$ ), higher than 79\%, while EAT-materials presented a majority of mesopores. The micropore volume remained around $\sim 0.21 \mathrm{~cm}^{3}$ $\mathrm{g}^{-1}$ in almost all cases. Regarding the presence of heteroatoms, the AT-route introduced the highest amount of nitrogen into the material with a maximum of $8.1 \mathrm{wt}$. \% for HTC carried out at $220^{\circ} \mathrm{C}$. The oxygen content decreased with the temperature, regardless of the functionalization route, remaining between 5.6 and 15.9 wt. $\%$.

The electrochemical performances of carbon materials derived from $\mathrm{HTC}$ at 180 and $210^{\circ} \mathrm{C}$ were evaluated (Braghiroli et al., 2015b). Electrodes for symmetrical SCs were prepared by mixing the powdered carbon material with carbon black and PVDF (75:5:20 wt. \%), and assembled in a T-type cell, using $4 \mathrm{M}$ $\mathrm{H}_{2} \mathrm{SO}_{4}$ as electrolyte. $\mathrm{CV}$ tests were carried out using a potential window of $1 \mathrm{~V}$. The obtained curves were asymmetric, indicating the existence of considerable resistance; examples are shown in Figure 10D. CV curves also showed humps characteristic of redox reactions occurring due to the high content of heteroatoms ( $\mathrm{N}$ and $\mathrm{O}$ ). Thanks to the pseudocapacitance contributions of these reactions, $C_{e}$ reached values as high as $322 \mathrm{~F} \mathrm{~g}^{-1}$ at $2 \mathrm{mV} \mathrm{s}^{-1}$. However, as the scan rate increased, $C_{e}$ dropped considerably. This behavior was attributed to the large size of the mesopores, $27-34 \mathrm{~nm}$, which do not significantly account for the capacitance and do not successfully shorten the ion diffusion pathways as the narrower mesopores would. In order to study the effect of doping, the interfacial capacitance was calculated by 
TABLE 2 | Hazard statements for phenol, resorcinol, formaldehyde, and tannin with data from the Kim et al. (2018) and the National Institute for Occupational Safety Health (2018).

\begin{tabular}{|c|c|c|c|c|}
\hline & Phenol & Resorcinol & Formaldehyde & Tannin \\
\hline REL & $\begin{array}{l}\text { TWA } 5 \text { ppm (skin) } \\
\text { STEL } 15.6 \text { ppm (skin) }\end{array}$ & $\begin{array}{l}\text { TWA } 10 \text { ppm } \\
\text { STEL } 20 \text { ppm }\end{array}$ & $\begin{array}{l}\text { TWA } 0.016 \text { ppm } \\
\text { STEL } 0.1 \text { ppm }\end{array}$ & \\
\hline
\end{tabular}

GHS and NFPA
hazards

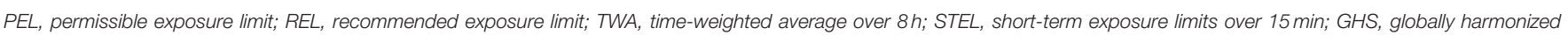
system; NFPA, National fire protection association. *According to SilvaChimica (St Michelle Mondovi, Italy), provider of mimosa, quebracho, and tara tannins.

TABLE 3 | Summary of methods, properties and electrochemical performance of tannin-derived carbon materials.

\begin{tabular}{|c|c|c|c|c|c|c|c|c|}
\hline $\begin{array}{l}\text { Tannin precursor/ } \\
\text { Synthesis method }\end{array}$ & Carbon material & $\begin{array}{l}\text { Activation/ } \\
\text { Doping }\end{array}$ & $\begin{array}{l}\text { BET area } \\
\left(\mathrm{m}^{2} \mathrm{~g}^{-1}\right)\end{array}$ & Cell type & Electrolyte $\mathrm{P}$ & $\begin{array}{c}\text { Potential } \\
\text { window (V) }\end{array}$ & $C_{e}\left(F^{-1}\right)$ & References \\
\hline Mimosa/Sol-gel & Cryo-CGs & $-1-$ & $399-1420$ & $\mathrm{~T}$ & $4 \mathrm{M} \mathrm{H}_{2} \mathrm{SO}_{4}$ & 1.0 & $30-109$, at $2 \mathrm{mV} \mathrm{s}^{-1}$ & Amaral-Labat et al., 2012 \\
\hline Mimosa/HTC & $\begin{array}{l}\text { Aero-, cryo- and } \\
\text { xero-CGs }\end{array}$ & $-/ \mathrm{N}, \mathrm{O}$ & 496-864 & $\mathrm{T}$ & $4 \mathrm{M} \mathrm{H}_{2} \mathrm{SO}_{4}$ & 1.0 & $231-388$, at $2 \mathrm{mV} \mathrm{s}^{-1}$ & Braghiroli et al., 2015c \\
\hline Pine/HTC & CMSs and CG-like & $-/ \mathrm{N}, \mathrm{O}$ & $80-652$ & $\begin{array}{l}3-e \\
2-e\end{array}$ & $1 \mathrm{M} \mathrm{H}_{2} \mathrm{SO}_{4}$ & 0.9 & $\begin{array}{l}114-321 \text {, at } 0.5 \mathrm{mV} \mathrm{s}^{-1} \\
112-258 \text {, at } 0.1 \mathrm{~A} \mathrm{~g}^{-1}\end{array}$ & Sanchez-Sanchez et al., 2017b \\
\hline $\begin{array}{l}\text { Mimosa/Hard- } \\
\text { templating }\end{array}$ & OMCs & $-1-$ & 1006 & $\begin{array}{l}3-e \\
2-e\end{array}$ & $1 \mathrm{M} \mathrm{H}_{2} \mathrm{SO}_{4}$ & 0.8 & $\begin{array}{l}\sim 250, \text { at } 0.5 \mathrm{mVs}^{-1} \\
\sim 196, \text { at } 0.1 \mathrm{~A} \mathrm{~g}^{-1}\end{array}$ & Sanchez-Sanchez et al., 2017a \\
\hline $\begin{array}{l}\text { Mimosa/ Phase } \\
\text { separation }\end{array}$ & OMCs & $\mathrm{CO}_{2} /-$ & $563-1137$ & $\begin{array}{l}3-e \\
2-e\end{array}$ & $2 \mathrm{M} \mathrm{H}_{2} \mathrm{SO}_{4}$ & 0.8 & $\begin{array}{l}158-286 \text {, at } 0.5 \mathrm{mV} \mathrm{s}^{-1} \\
\text { Up to } 244 \text {, at } 0.1 \mathrm{~A} \mathrm{~g}^{-1}\end{array}$ & Sanchez-Sanchez et al., 2018 \\
\hline
\end{tabular}

$C_{e}$, specific electrode capacitance; HTC, hydrothermal carbonization; CGs, carbon gels; CMSs, carbon microspheres; MCs, mesoporous carbons; OMCs, ordered mesoporous carbons; T, T-type cell; 3-e, three-electrode cell; 2-e, two-electrode cell.

normalizing $C_{e}$ by the surface area and was plotted against the $\mathrm{O}$ and $\mathrm{N}$ contents (wt. \%), see Figures 10E,F. It was found that the interfacial capacitance increased with the $\mathrm{O}$ content, but showed a maximum value for an $\mathrm{N}$ content between 3 and $6 \mathrm{wt}$. \%. A large amount of heteroatoms is believed to block the pores, resulting in reduced electrochemical performance.

A follow-up study evaluated the electrochemical performances of $\mathrm{N}$-doped CGs produced by HTC of EAT (Braghiroli et al., 2015c). In this case, aqueous solutions of different concentrations of EAT were submitted to HTC at $180^{\circ} \mathrm{C}$ for $24 \mathrm{~h}$. The recovered products were then dried to produce organic aerogels, cryogels, or xerogels, and the latter materials were further carbonized at $900^{\circ} \mathrm{C}$ to obtain $\mathrm{N}$-doped
CGs. The materials exhibited both micro- and mesoporosity in a proportion of $\sim 40 / 60$, and the highest surface areas were obtained for the highest concentration of EAT, reaching a maximum of $864 \mathrm{~m}^{2} \mathrm{~g}^{-1}$. For all the CGs, the $\mathrm{N}$ content remained around 2.5 wt. \%, and an $\mathrm{O}$ content higher than 13.9 wt. \% was observed. Electrodes for symmetrical SCs were prepared and assembled as described above for AT- and EAT-materials. Again, the CV curves were asymmetrical with the characteristic humps due to redox reactions, similar to those displayed in Figure 10D. At a scan rate of $2 \mathrm{mV} \mathrm{s}^{-1}$, the ultramicropore volume was found to have more impact on the $C_{e}$ values than the surface area. The capacitance increased significantly up to an ultramicropore volume of $0.2 \mathrm{~cm}^{3} \mathrm{~g}^{-1}$, 


\section{A}

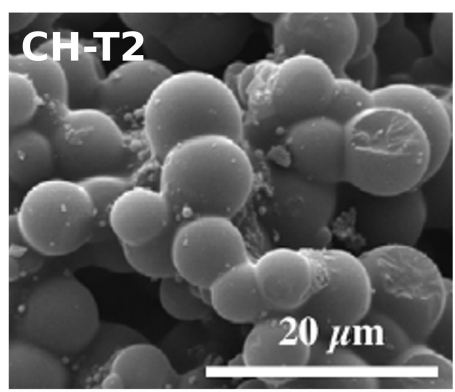

D

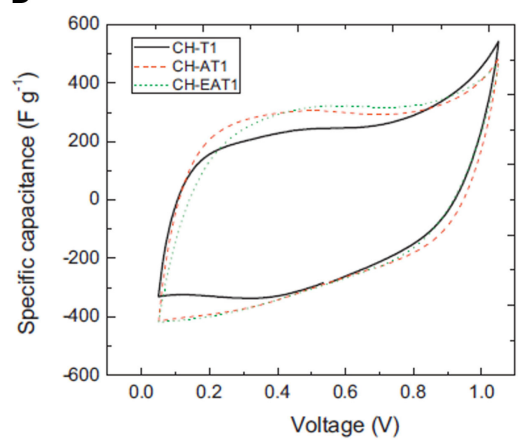

B

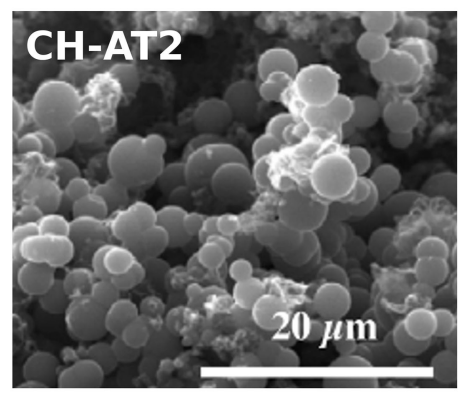

E

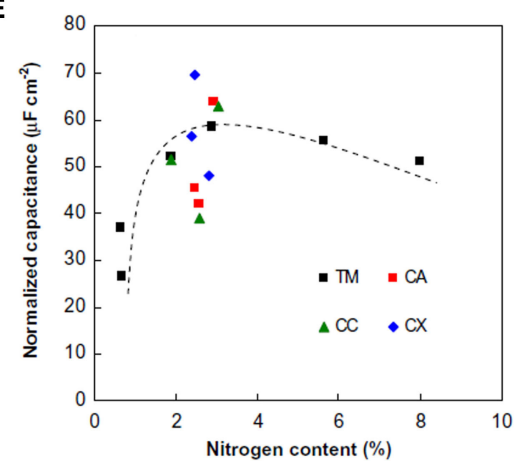

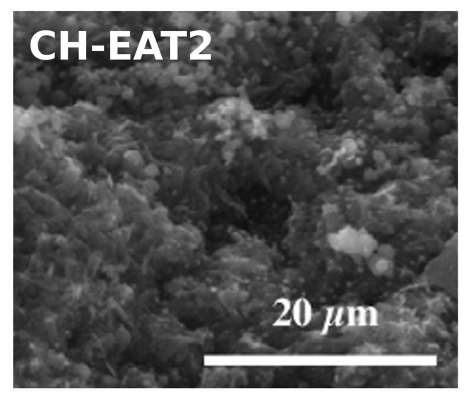

F

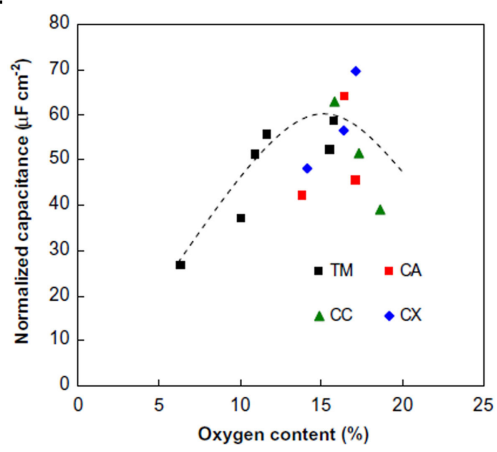

FIGURE 10 | SEM images of materials obtained after $\mathrm{HTC}$ at $210^{\circ} \mathrm{C}$ and subsequent pyrolysis at $900^{\circ} \mathrm{C}$ of tannin in: (A) water, or (B) ammonia solution, and (C) evaporated aminated tannin in water. (D) Examples of cyclic voltammetry curves obtained at $2 \mathrm{mV} \mathrm{s}^{-1}$ from carbonized (900 $\mathrm{C}^{\circ} \mathrm{HTC}$ materials produced at $180^{\circ} \mathrm{C}$ (Adapted with permission of Elsevier, from Braghiroli et al., 2015b; permission conveyed through Copyright Clearance Center, Inc.). Normalized capacitance as a function of (E) nitrogen and (F) oxygen content of: carbonized HTC materials produced at 180 and $210^{\circ} \mathrm{C}$, referred to as TM, and of EAT-derived CGs, referred to as CA, CC, and CX for carbon aerogels, cryogels and xerogels, respectively (Adapted with permission of Elsevier, from Braghiroli et al., 2015c; permission conveyed through Copyright Clearance Center, Inc.). The sample labels correspond to those used in their respective source references.

for which it reached a maximum value of $\sim 400 \mathrm{~F} \mathrm{~g}^{-1}$. A further increase in the volume did not affect the capacitance values. Contrary to what was expected, the values were more scattered than in the trends previously observed when comparing the effect of $\mathrm{O}$ and $\mathrm{N}$ doping on the interfacial capacitance with the results of Braghiroli et al. (2015b) (see again Figures 10E,F). Recalling that all CGs have a similar $\mathrm{N}$ content, this scattering might be due to their larger differences of pore texture. The enhancement in the capacitance due to $\mathrm{N}$-doping could be positively or negatively influenced by, for example, a larger or lower surface area, explaining the scattering of the values in Figure 10E. An analogous reasoning would also explain the behavior observed for the effect of the $\mathrm{O}$ content in Figure 10F.

Another study proved that $\mathrm{N}$-doped carbon materials can also be obtained by HTC treatment of aminated pine tannin (Sanchez-Sanchez et al., 2017b). The synthesis reported by Braghiroli et al. (2015b) was used by replacing mimosa tannin with pine tannin and carrying out the HTC process at $190^{\circ} \mathrm{C}$. The tannin extraction from Pinus pinaster was carried out by two methods. In method (i), a mix of pine bark and water in weight ratio of $1: 6$ was heated up to $90^{\circ} \mathrm{C}$ for $90 \mathrm{~min}$. In method (ii), the same mix used in (i) but in a 1:5 weight ratio was heated up to $75^{\circ} \mathrm{C}$; then, an aqueous solution containing 2 and $0.5 \%$ of $\mathrm{Na}_{2} \mathrm{SO}_{3}$ and $\mathrm{Na}_{2} \mathrm{CO}_{3}$, respectively, was added to the mixture while maintaining the temperature for an additional $60 \mathrm{~min}$. The suspensions from methods (i) and (ii) were filtered, washed with water and spray-dried, leading to tannin powders referred as TW or TNa, respectively. The morphology of the carbon materials was similar to that obtained from the same treatment of mimosa tannin, i.e., showing a transition from spherical particles to a gel-like structure. Most of the materials presented a high microporosity that led to surface areas between $\sim 300$ and $\sim 700 \mathrm{~m}^{2} \mathrm{~g}^{-1}$. However, samples obtained from the direct HTC of TNa and from the EAT-route did not develop any porous texture, which is the reason why they were excluded from the electrochemical tests.

A three-electrode configuration was used to evaluate the electrochemical performance of the pine tannin-derived materials in a potential window of $0.9 \mathrm{~V}$ in $1 \mathrm{M} \mathrm{H}_{2} \mathrm{SO}_{4}$. Electrodes were prepared by mixing the porous carbon, carbon black and PTFE (85:5:10 wt. \%). Faradaic peaks were observed on the $\mathrm{CV}$ curves at low scan rates $\left(0.5 \mathrm{mV} \mathrm{s}^{-1}\right)$. Remarkably, the TW-materials retained a quasi-rectangular CV curve for a high scan rate of $1 \mathrm{~V} \mathrm{~s}^{-1}$, but the deviations from the ideal rectangular shape suggest that the diffusion of ions in the narrow micropores was hindered. At low scan rate, $C_{e}$ of TW-materials was above $200 \mathrm{~F} \mathrm{~g}^{-1}$ due pseudocapacitance contributions. However, for a scan rate of $20 \mathrm{mV} \mathrm{s}^{-1}, C_{e}$ has already decreased to $\sim 40 \%$ 
of its original values because redox reactions do not occur at faster scan rates. Capacitance then continued to decrease but at a considerably slower rate, almost reaching a plateau at $1 \mathrm{~V} \mathrm{~s}^{-1}$. In addition, a linear increase in interfacial capacitance with the surface concentration of heteroatoms ( $\mathrm{N}$ and $\mathrm{O})$ was observed for the TW-materials. As the scan rate increased, the slope of the fitted line decreased, becoming almost a horizontal line at $1 \mathrm{~V} \mathrm{~s}^{-1}$. This implies that, for fast scan rates, the heteroatom content does not contribute to the capacitance, in agreement with the previous statements. TNa-A sample, obtained from aminated $\mathrm{TNa}$, exhibited the lowest performance, whatever the scan rate and despite a surface area and density of surface functionalities similar to those of other materials from the TW-series. Furthermore, TNa-A exhibited the lowest value of interfacial capacitance, indicating that a large part of the surface of the material was not accessible to the electrolyte ions. The high amount of surface functionalities was not able to compensate the lack of charge storage sites resulting in the poor performance observed. In addition, GCD and EIS measurements were carried out using a two-electrode cell. The calculation of $C_{e}$ from the GCD curves gave values similar to those obtained from the $\mathrm{CV}$ curves, and a drastic drop in capacitance was observed as the applied current increased. Again, TNa-A had the lowest performance. In general, the doped materials from the TW-series had the highest values of capacitance, confirming the beneficial role of surface modification. However, there are still some drawbacks to the doping procedure followed, as the EIS and GCD tests also revealed that the doped materials had larger EDR values and lower stability after continuous cycling than their non-doped counterparts.

\section{Microwave-Assisted Synthesis}

$\mathrm{P}$ - and N-doped carbons (PNDCs) have been successfully produced by a microwave technique using quebracho tannin as carbon precursor (Gopal Bairi et al., 2013). Melamine and hexamine were used as $\mathrm{N}$ source and polyphosphoric acid as $\mathrm{P}$ source. The synthesis was carried out by dissolving melamine and tannin in water, then a solution of hexamine was added and the whole mixture was heated to its boiling point. Finally, the resultant material was mixed with polyphosphoric acid and subjected to microwaves for $30 \mathrm{~min}$. The temperature reached was estimated to be between 1,200 and $1,400^{\circ} \mathrm{C}$ during the process carried out in a $1.25 \mathrm{~kW}-2.4 \mathrm{GHz}$ microwave oven. The physicochemical properties and performances of the PNDCs obtained from three different tannin:melamine:hexamine molar ratios as electrodes for SCs were further studied by the same research group (Nasini et al., 2014). The samples were referred to as PNDC- $x$, where $x=1,2$, or 3: the higher the value of $x$, the lower the amount of melamine and hexamine used for synthesis.

A large amount of heteroatoms was successfully introduced on the surface of the carbon. However, this was achieved by sacrificing considerably the available surface. The sample PNDC1 , having the highest content of surface functionalities ( $\mathrm{N} 9.7$ at. \%, P 9.0 at. \%, and O 14.9 at. \%), thus had the lowest BET area, $113 \mathrm{~m}^{2} \mathrm{~g}^{-1}$ due to an accumulation of heteroatoms that could hinder access to the pores. Moreover, the higher contents of $\mathrm{N}$ and $\mathrm{P}$ are the consequence of the use of large quantities of hexamine and polyphosphoric acid, both substances reducing the amount of gases released during pyrolysis, increasing the carbon yield, but also reducing the development of the porous texture. Decreasing the level of doping increased the surface area and increased the volumes of micro- and mesopores. The sample PNDC-3 thus had the lowest content of heteroatoms and exhibited a surface area of $855 \mathrm{~m}^{2} \mathrm{~g}^{-1}$ with a total pore volume of $0.65 \mathrm{~cm}^{3} \mathrm{~g}^{-1}$. Intermediate values of heteroatom content and textural properties were found for PNDC-2. PNDCs are mesoporous materials, and most of their pore volume is due to narrow mesopores (of width $\sim 3-4 \mathrm{~nm}$ ) at the levels of 99,78 , and $89 \%$ for PNDC-1, PNDC-2, and PNDC-3, respectively.

The electrochemical performance of electrodes composed of PNDC, carbon black and PTFE (90:5:5 wt. \%) was evaluated in a three-electrode cell using either $1 \mathrm{M} \mathrm{H}_{2} \mathrm{SO}_{4}$ or $6 \mathrm{M} \mathrm{KOH}$ as electrolytes. The CV curves of all materials in acidic medium revealed the typical peaks associated with redox reactions. At $5 \mathrm{mV} \mathrm{s}^{-1}$, the calculated $C_{e}$ for PNDC-2 and PNDC3 was 272 and $246 \mathrm{~F} \mathrm{~g}^{-1}$ and, despite its low surface area, PNDC-1 exhibited a capacitance of $172 \mathrm{~F} \mathrm{~g}^{-1}$ mainly due to pseudocapacitance contributions. As expected, $C_{e}$ decreased for higher scan rates. A faster drop in capacitance was observed for PNDC-2 than for PNDC-3. At $100 \mathrm{mV} \mathrm{s}^{-1}$, PNDC-2 lost $30 \%$ of its capacitance, while PNDC-3 lost only $12 \%$. The higher content of heteroatoms of PNDC-2, compared to PNDC-3, implies that at low scan rate, the contributions of pseudocapacitance are larger. However, at faster rates, redox reactions no longer occur, which reduces the performance of the material. On the other hand, the more stable performance of PNDC-3 is explained by the strong presence of mesopores and a low content of heteroatoms. Thus, for this material, the charge is mainly stored by an EDL mechanism that is not affected by an increase in the scan rate because the mesopores facilitate the diffusion of ions. In alkaline medium, PNDC-3 exhibited a behavior similar to that in acidic medium. However, lower values of $C_{e}$ were reached; this decrease in capacitance might be caused by the larger size and lower mobility of ions in $\mathrm{KOH}$, compared to those in $\mathrm{H}_{2} \mathrm{SO}_{4}$ (see Table 1). PNDC-2 exhibited the best performance of the series across the range of scan rates, attributed to a combination of sufficiently high surface area, pore volume and pseudocapacitance contribution of the surface functionalities that are reactive in alkaline media. Subsequent studies have extended this synthesis method to produce PNDCs from aminated quebracho tannin (Bairi et al., 2015) and Si- and P-doped carbons from quebracho tannin (Ramasahayam et al., 2015). In both studies, behaviors and values of capacitance similar to those detailed above were found.

\section{Hard-Templating}

OMCs have been produced by hard-templating using mimosa tannin and other tannin-related molecules such as phloroglucinol, gallic acid, and catechin (Sanchez-Sanchez et al., 2017a). SBA-15 silica template was synthesized using a mixture of tetraethyl orthosilicate (TEOS), Pluronic ${ }^{\circledR} \mathrm{P} 123, \mathrm{HCl}$, and water (molar ratio 1:0.017:6.04:145.8) that was stirred at $40^{\circ} \mathrm{C}$ for $4 \mathrm{~h}$ and aged at $125^{\circ} \mathrm{C}$ for $72 \mathrm{~h}$. The product, recovered by filtration, was heat-treated in air at $550^{\circ} \mathrm{C}$ for $6 \mathrm{~h}$. An ethanol solution of 
the corresponding precursor $(0.01 \mathrm{~mol} / 40 \mathrm{~mL})$ was added to the SBA- 15 , previously degassed under vacuum $\left(150^{\circ} \mathrm{C}, 2 \mathrm{~h}\right)$. Ethanol was evaporated under vacuum and, if necessary, the obtained solid was washed with deionized water to eliminate the excess of precursor deposited on the silica particles. These composites were carbonized under nitrogen flow according to a two-step temperature program: heating from room temperature to $100^{\circ} \mathrm{C}$ $\left(1^{\circ} \mathrm{C} \min ^{-1}\right)$ and holding the temperature for $2 \mathrm{~h}$ in order to remove moisture and polymerize the precursors, then heating up to $900^{\circ} \mathrm{C}\left(2^{\circ} \mathrm{C} \mathrm{min}^{-1}\right)$ and holding the temperature for $1 \mathrm{~h}$. The template was removed from the carbonized composites with $\mathrm{HF}$, washed with deionized water and finally dried at $80^{\circ} \mathrm{C}$ for $12 \mathrm{~h}$. The OMCs were labeled according to their precursors as TanC, $\mathrm{PhC}, \mathrm{GaC}$, and CatC for tannin, phloroglucinol, gallic acid, and catechin, respectively.

Figure 11A shows the schematic synthesis process and TEM images of the produced OMCs. TEM images revealed some discontinuities in the structure for CatC and TanC, indicating that catechin and mimosa tannin permeated the template heterogeneously. The large size of these molecules could block some of the pores, preventing the complete filling of the template and resulting in the gaps observed. XRD measurements revealed that all materials exhibited a structure in the $p 6 \mathrm{~mm}$ space group (2D hexagonal), and that the long-range order decreased as the size of the precursor molecule increased, in agreement with TEM results. Nevertheless, TanC had the advantage of achieving the highest carbon yield (80\%) among the carbon precursors used for this study. The textural characterization showed that all the OMCs exhibited BET surface areas of $\sim 1,000 \mathrm{~m}^{2} \mathrm{~g}^{-1}$ and total pore volumes higher than $0.87 \mathrm{~cm}^{3} \mathrm{~g}^{-1}$, of which $75-87 \%$ came from mesopores. Chemical characterization by elemental analysis and XPS revealed oxygen as the main heteroatom in the material, which was expected given its abundance in the precursor molecules.

The electrochemical performance was evaluated in $1 \mathrm{M}$ $\mathrm{H}_{2} \mathrm{SO}_{4}$. CV tests were carried out in a three-electrode cell while GCD and EIS measurements were done in a two-electrode cell. The electrodes, prepared by mixing the OMC, carbon black and PTFE (85:5:10 wt. \%), were spread onto graphite foil and pressed at $5 \mathrm{MPa}$. Rectangular $\mathrm{CV}$ curves were observed up to a scan rate of $100 \mathrm{mV} \mathrm{s}^{-1}$. At $0.5 \mathrm{mV} \mathrm{s}^{-1}, C_{e}$ reached values higher than $200 \mathrm{~F} \mathrm{~g}^{-1}$, which are in the same range of other carbons with similar textural properties but that required additional oxidation post-treatments (Jurewicz et al., 2004; Tanaka et al., 2015). GCD tests led to quasi-triangular curves whose slight curvature suggests the occurrence of redox reactions due to the presence of oxygen on the surface. For both CV and GCD tests, as the charging rate increased (scan rate or applied current), $C_{e}$ decreased. In particular, TanC presented a capacitance retention of $42 \%$ at $100 \mathrm{mV} \mathrm{s}^{-1}$ and $51 \%$ at $12 \mathrm{~A} \mathrm{~g}^{-1}$, higher than the $\sim 30 \%$ retention reported for the pine tannin-derived HTC carbons described above and tested under similar conditions (Sanchez-Sanchez et al., 2017b). The enhanced performance of OMCs as electrodes for SCs confirms the beneficial role of a hierarchical porous structure as a means of improving ion diffusion in the carbon material.

\section{Soft-Templating \\ Phase Separation}

Mimosa tannin was successfully used as precursor to produce OMCs by an easy and simple phase-separation method (Braghiroli et al., 2016). The synthesis only required the mixing, at room temperature, of two solutions: one of mimosa tannin, the other of Pluronic ${ }^{\circledR}$ F127. Immediately after mixing, a phaseseparation occurred and after 2 days, complete sedimentation of the resultant mesophase was observed. The recovered mesophase was dried at $80^{\circ} \mathrm{C}$ and carbonized at temperatures ranging from 400 to $900^{\circ} \mathrm{C}$. The $\mathrm{pH}$ of the tannin solution was varied from 0 to 4.2 but no significant change in the carbon yield or the porosity were observed by modifying this parameter. The synthesis process is shown in Figure 11B, and TEM images of OMCs obtained for different $\mathrm{pH}$ values are presented. Thermogravimetric analysis showed that the Pluronic ${ }^{\circledR}$ F127 degrades at $400^{\circ} \mathrm{C}$, so carbonization at higher temperatures is required to remove it completely from the material. Higher temperature treatments resulted in more developed microporosity and consequently higher surface areas: a maximum of $\sim 700 \mathrm{~m}^{2} \mathrm{~g}^{-1}$ BET area was reached. These values of surface area are $\sim 200 \mathrm{~m}^{2} \mathrm{~g}^{-1}$ higher than those obtained from an EISA method also using mimosa tannin as precursor and carbonizing the mesophase at a maximum temperature of $850^{\circ} \mathrm{C}$ (Schlienger et al., 2012).

Some modifications to the phase-separation method were made in a following study that also investigated the effect of the assembly temperature (Sanchez-Sanchez et al., 2018). The pH was varied from 1 to 4.5 and the assembly temperature ranged from 10 to $30^{\circ} \mathrm{C}$. The mixed tannin/F127 solutions were keep at a constant assembly temperature for $72 \mathrm{~h}$, and then they remained at room temperature for 5 days until complete phase-separation. The retrieved resins were dried at $60^{\circ} \mathrm{C}$ and carbonized in two consecutive steps: increasing the temperature up to $400^{\circ} \mathrm{C}$, holding it for $4 \mathrm{~h}$, and then heating until $900^{\circ} \mathrm{C}$ and holding for $1 \mathrm{~h}$. In agreement with the previous work of Braghiroli et al. (2016), it was found that for a fixed temperature, the $\mathrm{pH}$ did not change considerably the porous texture. On the contrary, for a given $\mathrm{pH}$, an effect of the assembly temperature was observed, where the greatest change occurred at $\mathrm{pH} 3$ after increasing the temperature from 20 to $30^{\circ} \mathrm{C}$. The solution of $\mathrm{pH} 3$ assembled at $30^{\circ} \mathrm{C}$ gave the carbon material, called F3/30, having the highest values of surface area and micro- and mesopore volumes, $750 \mathrm{~m}^{2}$ $\mathrm{g}^{-1}, 0.24$ and $0.49 \mathrm{~cm}^{3} \mathrm{~g}^{-1}$, respectively. Therefore, F3/30 was selected for $\mathrm{CO}_{2}$ activation to improve its porous texture further.

As expected, for the resultant activated carbon, labeled C3/30, an increased surface area $\left(\sim 1,100 \mathrm{~m}^{2} \mathrm{~g}^{-1}\right)$ and a widening of pores were observed. Three- and two-electrode cells were used for its electrochemical characterization, using $2 \mathrm{M} \mathrm{H}_{2} \mathrm{SO}_{4}$ as electrolyte and electrodes composed of a mixture of the studied carbon, carbon black and PTFE (85:5:10 wt. \%). It was found that the main mechanism of storage of energy was the EDL, since the contribution of pseudocapacitance from heteroatoms was negligible. In addition, CV and GCD tests showed that the activation process increased the capacitance of the material by 1.5 times, probably due to the widening and 


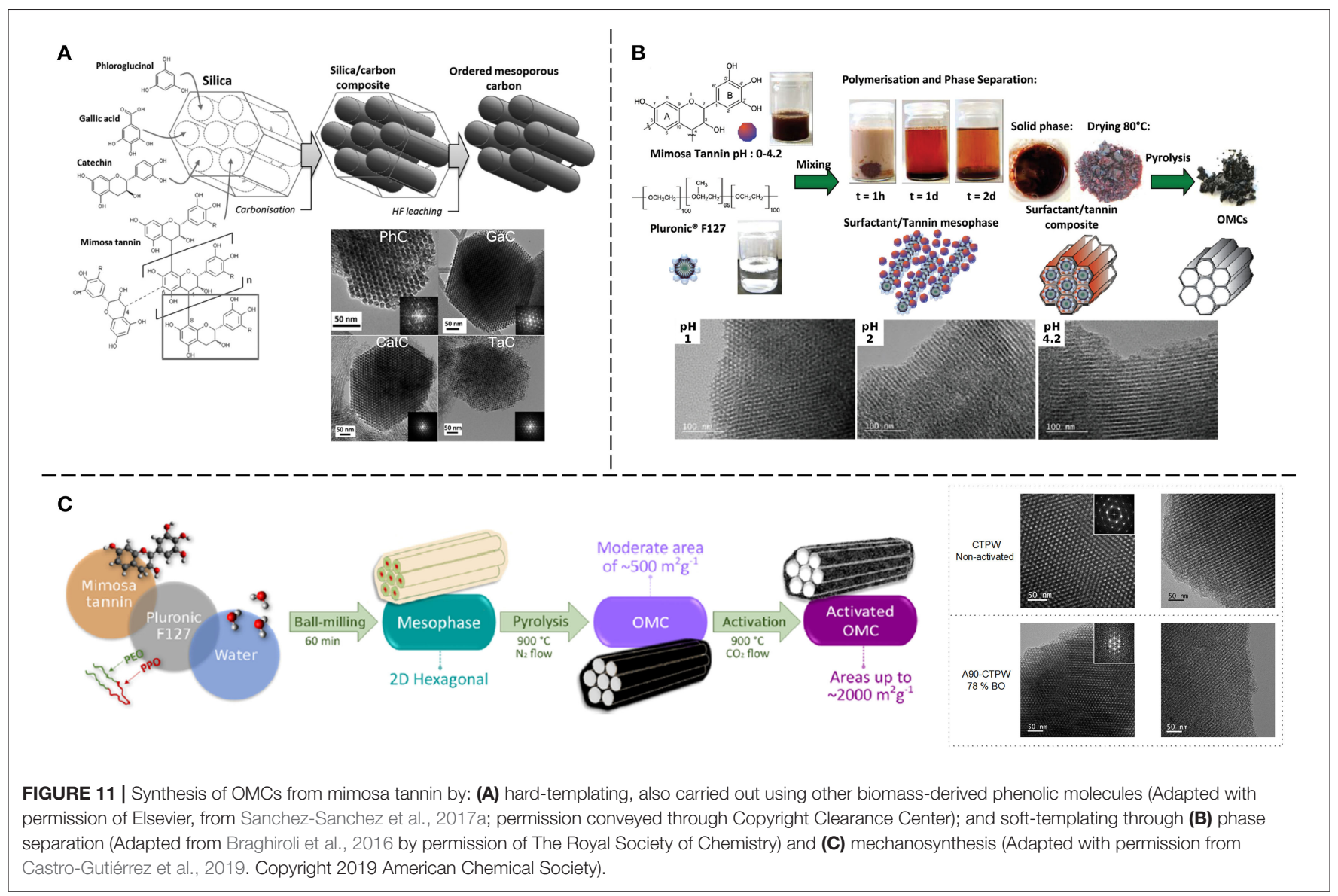

opening of previously blocked pores, which resulted in improved connectivity of the pore network and surface accessibility to electrolyte ions. Even more, the electrochemical tests showed that the rate capabilities of $\mathrm{C} 3 / 30$ were comparable to those measured for the hard-templated TanC obtained from the same precursor, mimosa tannin, but through a less eco-friendly synthesis method (Sanchez-Sanchez et al., 2017a), thus showing the advantage of the soft-template method.

\section{Mechanosynthesis}

Mechanosynthesis methods, for which mechanical energy is supplied to the materials by shearing, stretching, or grinding (James et al., 2012), are commonly used to produce ceramics, metal alloys, and organic materials (Kaupp, 2009, 2011; Wang, 2013). This type of solid-state synthesis has attracted interest for producing OMCs since they require little or no solvent, short synthesis times compared to other methods and fewer synthesis steps, which results in cheaper and more eco-friendly products (James et al., 2012; Wang, 2013; Zhu et al., 2016). Ball-milling has been found to be an appropriate method for synthesizing OMCs, as it can provide higher energy and repeatability than manual grinding, thereby increasing its potential for use on an industrial scale (Wang, 2013). OMCs were indeed obtained by ball-milling mimosa tannin, Pluronic ${ }^{\circledR}$ F127 and metal acetates used as crosslinkers. After washing, drying and carbonization, 2D hexagonal geometries were observed (Zhang et al., 2017).
More recently, another study reported an easy, one-pot mechanosynthesis method for preparing OMCs with a 2D hexagonal structure by ball-milling, where only mimosa tannin (T), Pluronic ${ }^{\circledR}$ F127 (P) and small amounts of water (W) were needed (Castro-Gutiérrez et al., 2018). This surfactantwater-assisted mechanochemical mesostructuration (SWAMM) method does not involve curing or drying steps before carbonization or the use of hazardous substances as crosslinkers. The influence of synthesis parameters such as milling time, $\mathrm{pH}, \mathrm{P}: \mathrm{W}$ weight ratio and carbonization temperature on the textural properties of the obtained carbon materials was analyzed. Optimal values of milling time $(60 \mathrm{~min})$ and $\mathrm{pH}$ (unchanged) to produce uniform PSDs were found and it was shown that by changing the $\mathrm{P}: \mathrm{W}$ weight ratio, it was possible to produce either ordered or disordered mesoporous materials. Increasing the carbonization temperature from 900 to $1,100^{\circ} \mathrm{C}$ resulted in the development of micro- and mesoporosity, but higher temperatures, up to $1,500^{\circ} \mathrm{C}$, did not seem to have a significant impact on the textural properties of the OMCs. Nonetheless, Raman spectra revealed that despite being in the non-graphitizable regime, higher carbonization temperatures yielded materials with improved long-range order at the nanoscale. Several applications were explored with promising results, such as the adsorption of hydrocarbons from water, the adsorption of $\mathrm{CO}_{2}$ and, after activation, the storage of energy in SCs. 
Energy storage in SCs was further investigated in a followup study, where the electrochemical performances of activated OMCs (AOMCs) produced by the SWAMM method were evaluated (Castro-Gutiérrez et al., 2019). The OMC was placed inside a tubular furnace and heated up to $900^{\circ} \mathrm{C}\left(5^{\circ} \mathrm{C} \mathrm{min}^{-1}\right)$ under $\mathrm{N}_{2}$ flow, then $\mathrm{N}_{2}$ was switched to $\mathrm{CO}_{2}$ to physically activate the samples for durations ranging from 15 to $120 \mathrm{~min}$. The samples were labeled At-CTPW with $t$ standing for the time in minutes. TEM images of as-synthesized and A90-CTPW materials are shown in Figure 11C with a scheme of the synthesis method. It was observed that the ordered mesoporous structure was maintained up to a burn-off of $78 \%$ (A90-CTPW). The surface area of the AOMCs increased with burn-off, reaching a maximum of $\sim 2,000 \mathrm{~m}^{2} \mathrm{~g}^{-1}$ for a burn-off of $\sim 80 \%$. Higher activation times resulted in a sudden decrease of surface area due to pore widening and merging, evidenced by the PSDs and the derived calculations of ultramicro-, supermicro- $(0.7<$ pore width $<2 \mathrm{~nm}$ ) and mesopore volumes. Electrodes were prepared with samples A30- to A-90-CTPW that were mixed with carbon black and PTFE (85:5:10 wt. \%) to form a paste from which electrodes with carbon loads of $\sim 10 \mathrm{mg} \mathrm{cm}^{-2}$ were cut and assembled in a two-electrode cell.

$\mathrm{CV}$ tests performed in $1 \mathrm{M} \mathrm{H}_{2} \mathrm{SO}_{4}$ revealed rectangular curves at $5 \mathrm{mV} \mathrm{s}^{-1}$, with $C_{e}$ values between 136 and $160 \mathrm{~F} \mathrm{~g}^{-1}$, the maximum being reached by A75-CTPW. Only A60- and A75CTPW retained more than $60 \%$ of their initial capacitance at $500 \mathrm{mV} \mathrm{s}^{-1}$, which was attributed to a combination of high surface area originating from a high micropore volume $\left(<0.50 \mathrm{~cm}^{3} \mathrm{~g}^{-1}\right)$, providing multiple charge storage sites, and a suitable PSD, favoring ion diffusion at high charging rates. A further characterization was then carried out on these samples, using also $1 \mathrm{M} \mathrm{TEABF}_{4} / \mathrm{ACN}$ as electrolyte. Examples of $\mathrm{CV}$ curves in aqueous and organic electrolytes are shown in Figures 12A,D. During GCD tests, A60- and A75-CTPW exhibited triangular curves in the aqueous electrolyte. However, A75-CTPW performed better once the applied current increased, showing a capacitance retention, $C_{r e t}$, of $70 \%$, whereas that observed for A60-CTPW was only 51\%, both at a high current of $80 \mathrm{~A} \mathrm{~g}^{-1}$, see Figure 12B. In the organic electrolyte, A60and A75-CTPW behaved in a similar way and a more rapid drop of $C_{r e t}$ was observed compared to that in the aqueous electrolyte (Figure 12E). This was ascribed to the larger size and lower mobility of the ions in the organic electrolyte that increased the resistance of the SC cell, thereby decreasing its performance. In all cases, the tannin-derived AOMCs presented superior or comparable rate capabilities than those previously reported for similar materials (also displayed in Figures 12B,E) with the advantage of being produced by an easy and eco-friendly method. Even more, A60- and A75-CTPW exhibited great longterm stability over time and after continuous cycling at $5 \mathrm{~A} \mathrm{~g}^{-1}$. More precisely, in the aqueous electrolyte, $C_{\text {ret }}$ remained at $\sim 98 \%$ after 10,000 cycles and $\sim 94 \%$ after $50 \mathrm{~h}$ of potentiostatic hold at $1 \mathrm{~V}$, while in the organic electrolyte $C_{\text {ret }}$ was above $90 \%$ after 8,000 cycles and reached $86 \%$ after $72 \mathrm{~h}$ of potentiostatic hold at $2.7 \mathrm{~V}$.

As expected, the values of $E$ and $P$ in organic electrolyte are considerably higher than in aqueous electrolyte, see Figures 12C,F. Indeed, a maximum $E$ of $28 \mathrm{Wh} \mathrm{kg}^{-1}$ (at a $P$ output of $138 \mathrm{~W} \mathrm{~kg}^{-1}$ ) was attained in the organic electrolyte, more than 5 times the maximum $E$ of $5 \mathrm{Wh} \mathrm{kg}^{-1}$ (at a $P$ output of $44 \mathrm{~W} \mathrm{~kg}^{-1}$ ) reached in the aqueous electrolyte. For the organic electrolyte, it is important to note that, despite the drastic drop in $E$ observed, the selected AOMCs were still able to store $\sim 13$ Wh kg ${ }^{-1}$ at a high $P$ of $12 \mathrm{~kW} \mathrm{~kg}^{-1}$. Finally, the electrochemical performances of the selected AOMCs were also evaluated in $1 \mathrm{M}$ $\mathrm{Na}_{2} \mathrm{SO}_{4}$, a neutral aqueous electrolyte. The results are shown in Figures 12G-I. In general, lower values of $C_{e}$ and $C_{r e t}$ were found compared to those obtained in acidic medium $\left(\mathrm{H}_{2} \mathrm{SO}_{4}\right)$. The lower performance of the SCs in $\mathrm{Na}_{2} \mathrm{SO}_{4}$ can be related to a larger size and lower mobility of the $\mathrm{Na}^{+}$ion. The larger size results in fewer charge storage sites, leading to a lower capacitance while the lower mobility hinders diffusion at high charging rates. Nevertheless, the advantage of the neutral electrolyte lies in the possibility of extending the operating potential window. Consequently, an increase of $\sim 60 \%$ of the maximum $E$ was observed with respect to that reached in acidic medium.

\section{SUMMARY AND PERSPECTIVES}

SCs are devices with high power outputs, rate capability, cyclability, and long lifetimes. However, the amount of stored energy in SCs is lower than that found in batteries. In this sense, research in recent decades has focused on the development of new materials that can improve SC performance, not only by increasing the storage capacity but also by increasing the rate capability and the long-term stability. Porous carbons have proven to be adequate materials for SC electrodes and, indeed, ACs are already widely used in commercial devices. Multiple synthesis methods have been developed to control the textural and chemical properties of porous carbons; in particular, templated carbons, such as OMCs, are promising electrode materials because they can be produced with different morphologies, high surface area and adjusted hierarchical porosity. The possibility of tuning the pore size is of significant importance as it allows full accessibility of the electrolyte into the material, while the hierarchical structure provides channels facilitating the diffusion of ions toward the smallest accessible pores. The modification of the surface chemistry of porous carbons presents another route to increase SC performance, and doping with oxygen, nitrogen or other heteroatoms can induce redox reactions that increase the energy stored in the device. Even if all the surface functionalities do not always induce redox reactions, doping can also improve other characteristics of the material such as electrical conductivity, wettability, or stability.

Besides, the quest for environmentally friendly technologies has pushed research to find substitutes for synthetic and hazardous molecules commonly used as carbon precursors or crosslinkers. Among the various biosourced precursors, tannins are excellent alternatives to petrochemical carbon sources because of their phenolic nature. In addition, condensed tannins have a reactivity similar to that of phenol or resorcinol, so tannins can replace them in already established synthesis methods. The autocondensation property of condensed tannins also offers the opportunity of avoiding the use of crosslinkers, which 
Aqueous electrolyte $\left(\mathrm{H}_{2} \mathrm{SO}_{4}\right)$

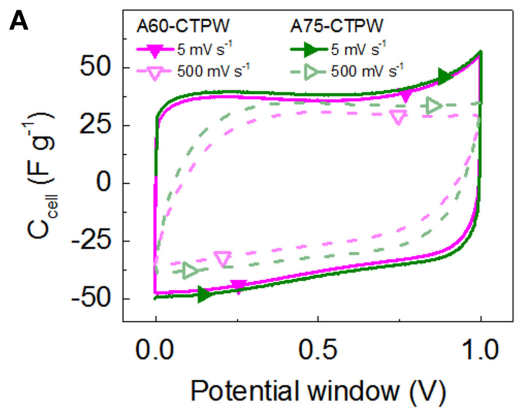

Organic electrolyte $\left(\mathrm{TEABF}_{4} / \mathrm{ACN}\right)$

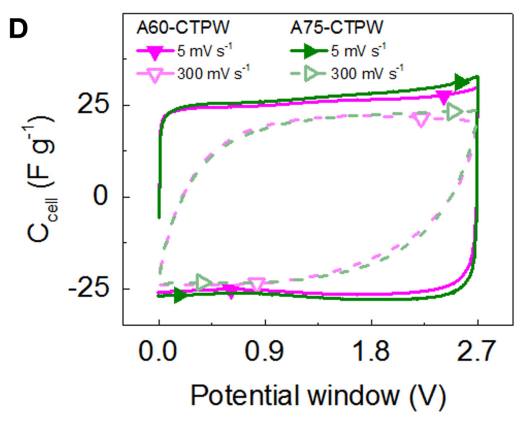

Aqueous electrolyte $\left(\mathrm{Na}_{2} \mathrm{SO}_{4}\right)$

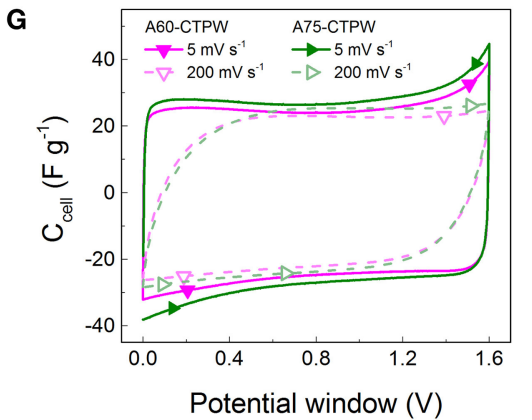

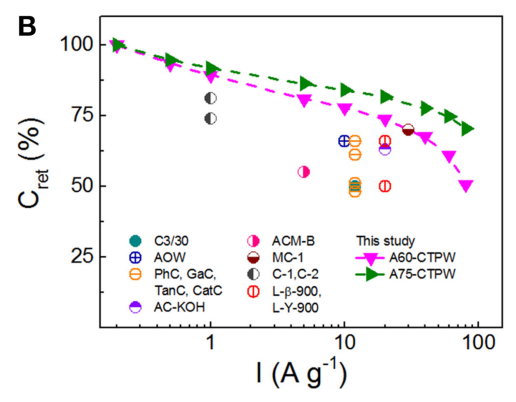

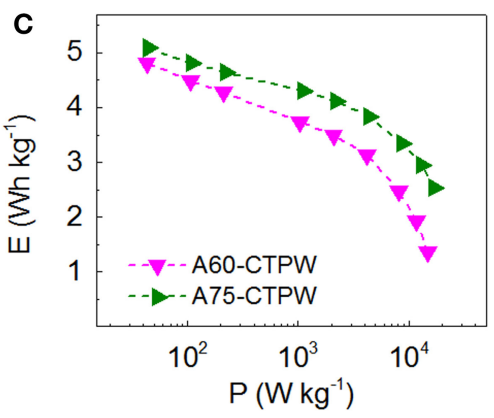

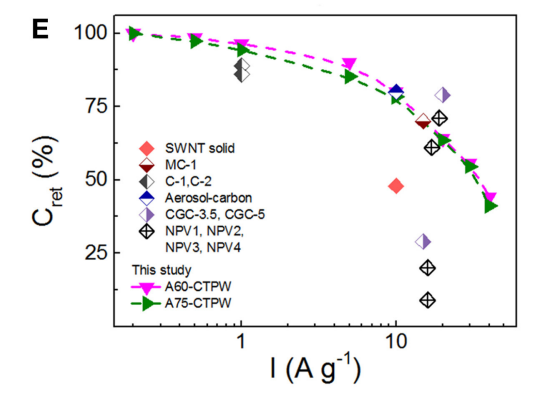

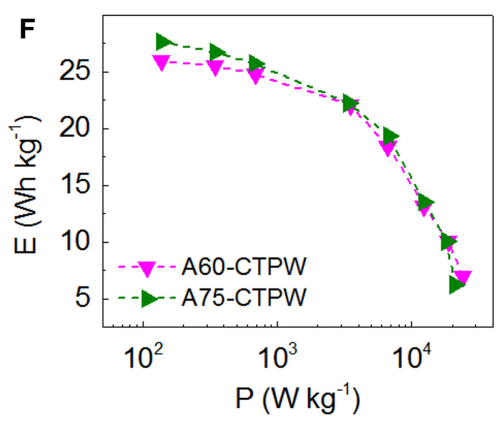

FIGURE 12 | Electrochemical performances of activated OMCs derived from mimosa tannin: (A,D,G) CV curves; (B,E,H) capacitance retention as a function of applied current; and (C,F,I) specific energy as a function of specific power (Ragone-like graphs) calculated from the GCD curves. The tests were carried out in (A-C) $1 \mathrm{M} \mathrm{H}_{2} \mathrm{SO}_{4}$ aqueous electrolyte (acidic medium), (D-F) $1 \mathrm{M} \mathrm{TEABF}_{4} / \mathrm{ACN}$ organic electrolyte and (G-I) $1 \mathrm{M} \mathrm{Na}_{2} \mathrm{SO}_{4}$ aqueous electrolyte (neutral medium). (Adapted with permission from Castro-Gutiérrez et al., 2019. Copyright 2019 American Chemical Society).

makes them suitable precursors for self-assembly methods. As described in the last section of this review, several studies have demonstrated the versatility of tannins to produce porous carbon materials through "green" processes reducing or even eliminating the use of toxic or hazardous substances and thus decreasing their negative environmental impact. In addition, tannins are extracted industrially and marketed on a large scale, because they are essential for the leather, wine and food industry. Therefore, they are readily available at low cost. Thus, the production of porous carbons from tannin will provide and add value to this precursor derived from biomass.

In general, the main disadvantages of producing advanced porous carbon materials are their complex multi-step procedures and their tedious synthesis. Therefore, future materials research efforts for SCs should continue to focus on the development and optimization of easy and environmentally friendly procedures such as one-pot synthesis methods that allow for in situ doping and/or activation of biomass or biosourced precursors. 
Simplifying and reducing the number of steps would reduce costs and increase scalability, resulting in a use of biosourced carbons that is more widespread in commercial SC devices.

\section{AUTHOR CONTRIBUTIONS}

JC-G performed writing original draft and conceptualization. AC performed writing-review and editing. VF performed conceptualization, supervision, funding acquisition, and writing-review and editing. All authors contributed to the article and approved the submitted version.

\section{REFERENCES}

Acosta, R., Nabarlatz, D., Sánchez-Sánchez, A., Jagiello, J., Gadonneix, P., Celzard, A., et al. (2018). Adsorption of bisphenol A on $\mathrm{KOH}$-activated tyre pyrolysis char. J. Environ. Chem. Eng. 6, 823-833. doi: 10.1016/j.jece.2018.01.002

Amaral-Labat, G., Grishechko, L. I., Fierro, V., Kuznetsov, B. N., Pizzi, A., and Celzard, A. (2013). Tannin-based xerogels with distinctive porous structures. Biomass Bioenergy 56, 437-445. doi: 10.1016/j.biombioe.2013.06.001

Amaral-Labat, G., Szczurek, A., Fierro, V., Stein, N., Boulanger, C., Pizzi, A., et al. (2012). Pore structure and electrochemical performances of tannin-based carbon cryogels. Biomass Bioenergy 39, 274-282. doi: 10.1016/j.biombioe.2012.01.019

Aneke, M., and Wang, M. (2016). Energy storage technologies and real life applications - a state of the art review. Appl. Energy 179, 350-377. doi: 10.1016/j.apenergy.2016.06.097

Ayala, P., Arenal, R., Rümmeli, M., Rubio, A., and Pichler, T. (2010). The doping of carbon nanotubes with nitrogen and their potential applications. Carbon 48 , 575-586. doi: 10.1016/j.carbon.2009.10.009

Bairi, V. G., Nasini, U. B., Kumar Ramasahayam, S., Bourdo, S. E., and Viswanathan, T. (2015). Electrocatalytic and supercapacitor performance of phosphorous and nitrogen co-doped porous carbons synthesized from aminated tannins. Electrochim. Acta 182, 987-994. doi: 10.1016/j.electacta.2015.10.011

Bard, A. J., and Faulkner, L. R. (2001). Electrochemical Methods: Fundamentals and Applications, 2 Edn. Hoboken, NJ: Wiley.

Basta, A. H., Fierro, V., El-Saied, H., and Celzard, A. (2009). 2-Steps $\mathrm{KOH}$ activation of rice straw: an efficient method for preparing highperformance activated carbons. Bioresour. Technol. 100, 3941-3947. doi: 10.1016/j.biortech.2009.02.028

Beguin, F., and Frackowiak, E (Eds.). (2013). Supercapacitors: Materials, Systems, and Applications. Weinheim: John Wiley \& Sons, Ltd.

Berenguer, R., Nishihara, H., Itoi, H., Ishii, T., Morallón, E., Cazorla-Amorós, D., et al. (2013). Electrochemical generation of oxygen-containing groups in an ordered microporous zeolite-templated carbon. Carbon 54, 94-104. doi: 10.1016/j.carbon.2012.11.007

Braghiroli, F. L., Amaral-Labat, G., Boss, A., Lacoste, C., and Pizzi, A. (2019). Tannin gels and their carbon derivatives: a review. Biomolecules 9:587. doi: 10.3390/biom9100587

Braghiroli, F. L., Fierro, V., Izquierdo, M. T., Parmentier, J., Pizzi, A., and Celzard, A. (2012). Nitrogen-doped carbon materials produced from hydrothermally treated tannin. Carbon 50, 5411-5420. doi: 10.1016/j.carbon.2012.07.027

Braghiroli, F. L., Fierro, V., Izquierdo, M. T., Parmentier, J., Pizzi, A., Delmotte, L., et al. (2015a). High surface - highly N-doped carbons from hydrothermally treated tannin. Ind. Crops Prod. 66, 282-290. doi: 10.1016/j.indcrop.2014.11.022

Braghiroli, F. L., Fierro, V., Parmentier, J., Pasc, A., and Celzard, A. (2016). Easy and eco-friendly synthesis of ordered mesoporous carbons by selfassembly of tannin with a block copolymer. Green Chem. 18, 3265-3271. doi: 10.1039/C5GC02788H

Braghiroli, F. L., Fierro, V., Szczurek, A., Stein, N., Parmentier, J., and Celzard, A. (2015b). Electrochemical performances of hydrothermal

\section{FUNDING}

This study was partly funded by the French PIA project Lorraine Université d'Excellence, reference ANR-15-IDEX-04-LUE and the TALiSMAN project, funded by FEDER (2019-000214).

\section{ACKNOWLEDGMENTS}

JC-G gratefully acknowledges CONACYT-SENER (601021/438978) for the scholarship awarded to support her Ph.D. studies, resulting in the work presented herein.

tannin-based carbons doped with nitrogen. Ind. Crops Prod. 70, 332-340. doi: 10.1016/j.indcrop.2015.03.046

Braghiroli, F. L., Fierro, V., Szczurek, A., Stein, N., Parmentier, J., and Celzard, A. (2015c). Hydrothermally treated aminated tannin as precursor of N-doped carbon gels for supercapacitors. Carbon 90, 63-74. doi: 10.1016/j.carbon.2015.03.038

CAPPEQ (2019a). How to Extract Tannin? Tannins. Available online at: https:// www.tannins.org/how-to-extract-tannin/ (accessed February 3, 2020).

CAPPEQ (2019b). Tannin, A History Close to Your Own. Tannins. Available online at: https://www.tannins.org/history-of-tannin/ (accessed February 3, 2020).

CAPPEQ (2019c). Tannin: One Substance, Different Applications. Tannins. Available online at: https://www.tannins.org/applications/ (accessed February 3, 2020).

Castro-Gutiérrez, J., Díez, N., Sevilla, M., Izquierdo, M. T., Ghanbaja, J., Celzard, A., et al. (2019). High-rate capability of supercapacitors based on tanninderived ordered mesoporous carbons. ACS Sust. Chem. Eng. 7, 17627-17635. doi: 10.1021/acssuschemeng.9b03407

Castro-Gutiérrez, J., Sanchez-Sanchez, A., Ghanbaja, J., Díez, N., Sevilla, M., Celzard, A., et al. (2018). Synthesis of perfectly ordered mesoporous carbons by water-assisted mechanochemical self-assembly of tannin. Green Chem. 20, 5123-5132. doi: 10.1039/C8GC02295J

Cha, J. S., Park, S. H., Jung, S.-C., Ryu, C., Jeon, J.-K., Shin, M.-C., et al. (2016). Production and utilization of biochar: a review. J. Industr. Eng. Chem. 40, 1-15. doi: 10.1016/j.jiec.2016.06.002

Chang, P.-Y., Bindumadhavan, K., and Doong, R.-A. (2015). Size effect of ordered mesoporous carbon nanospheres for anodes in li-ion battery. Nanomaterials 5, 2348-2358. doi: 10.3390/nano5042348

Chen, C.-M., Zhang, Q., Zhao, X.-C., Zhang, B., Kong, Q.-Q., Yang, M.-G., et al. (2012). Hierarchically aminated graphene honeycombs for electrochemical capacitive energy storage. J. Mater. Chem. 22:14076. doi: 10.1039/c2jm31426f

Chen, H., Liu, D., Shen, Z., Bao, B., Zhao, S., and Wu, L. (2015). Functional biomass carbons with hierarchical porous structure for supercapacitor electrode materials. Electrochim. Acta 180, 241-251. doi: 10.1016/j.electacta.2015.08.133

Ciszewski, M., Koszorek, A., Radko, T., Szatkowski, P., and Janas, D. (2019). Review of the selected carbon-based materials for symmetric supercapacitor application. J. Elec. Mater. 48, 717-744. doi: 10.1007/s11664-018-6811-7

Conte, M. (2010). Supercapacitors technical requirements for new applications. Fuel Cells 10, 806-818. doi: 10.1002/fuce.201000087

de Hoyos-Martínez, P. L., Merle, J., Labidi, J., and Charrier - El Bouhtoury, F. (2019). Tannins extraction: a key point for their valorization and cleaner production. J. Clean. Prod. 206, 1138-1155. doi: 10.1016/j.jclepro.2018.09.243

Delgado-Sánchez, C., Santiago-Medina, F., Fierro, V., Pizzi, A., and Celzard, A. (2018). Optimisation of "green" tannin-furanic foams for thermal insulation by experimental design. Mater. Des. 139, 7-15. doi: 10.1016/j.matdes.2017.10.064

Deng, Y., Xie, Y., Zou, K., and Ji, X. (2016). Review on recent advances in nitrogendoped carbons: preparations and applications in supercapacitors. J. Mater. Chem. A 4, 1144-1173. doi: 10.1039/C5TA08620E

Díez, N., Ferrero, G. A., Sevilla, M., and Fuertes, A. B. (2019). A sustainable approach to hierarchically porous carbons from tannic acid and their utilization in supercapacitive energy storage systems. J. Mater. Chem. A 7, 14280-14290. doi: 10.1039/C9TA01712G 
Elmouwahidi, A., Castelo-Quibén, J., Vivo-Vilches, J. F., Pérez-Cadenas, A. F., Maldonado-Hódar, F. J., and Carrasco-Marín, F. (2018). Activated carbons from agricultural waste solvothermally doped with sulphur as electrodes for supercapacitors. Chem. Eng. J. 334, 1835-1841. doi: 10.1016/j.cej.2017.11.141

Feinle, A., Elsaesser, M. S., and Hüsing, N. (2016). Sol-gel synthesis of monolithic materials with hierarchical porosity. Chem. Soc. Rev. 45, 3377-3399. doi: 10.1039/C5CS00710K

Feng, S., Li, W., Wang, J., Song, Y., Elzatahry, A. A., Xia, Y., et al. (2014). Hydrothermal synthesis of ordered mesoporous carbons from a biomassderived precursor for electrochemical capacitors. Nanoscale 6, 14657-14661. doi: 10.1039/C4NR05629A

Ferrero, G. A., Fuertes, A. B., and Sevilla, M. (2015). N-doped microporous carbon microspheres for high volumetric performance supercapacitors. Electrochim. Acta 168, 320-329. doi: 10.1016/j.electacta.2015.04.052

Fierro, V., Muñiz, G., Basta, A. H., El-Saied, H., and Celzard, A. (2010). Rice straw as precursor of activated carbons: activation with ortho-phosphoric acid. J. Hazard. Mater. 181, 27-34. doi: 10.1016/j.jhazmat.2010.04.062

Fierro, V., Sánchez-Sánchez, A., and Celzard, A. (2018). “Tannins as precursors of supercapacitor electrodes," in Sustainable Energy Technologies, eds E. RincónMejía and A. de las Heras (Boca Raton, FL: CRC Press), 201-228.

Fierro, V., Torné-Fernández, V., and Celzard, A. (2007). Methodical study of the chemical activation of Kraft lignin with $\mathrm{KOH}$ and $\mathrm{NaOH}$. Microp. Mesopor. Mater. 101, 419-431. doi: 10.1016/j.micromeso.2006.12.004

Fierro, V., Torné-Fernández, V., Montané, D., and Celzard, A. (2005). Study of the decomposition of kraft lignin impregnated with orthophosphoric acid. Thermochim. Acta 433, 142-148. doi: 10.1016/j.tca.2005.02.026

Frackowiak, E. (2007). Carbon materials for supercapacitor application. Phys. Chem. Chem. Phys. 9:1774. doi: 10.1039/b618139m

Frackowiak, E., and Beguin, F. (2001). Carbon materials for the electrochemical storage of energy in capacitors. Carbon 39, 937-950. doi: 10.1016/S0008-6223(00)00183-4

Frackowiak, E., Lota, G., Machnikowski, J., Vix-Guterl, C., and Béguin, F. (2006). Optimisation of supercapacitors using carbons with controlled nanotexture and nitrogen content. Electrochim. Acta 51, 2209-2214. doi: 10.1016/j.electacta.2005.04.080

Fuertes, A. B., Ferrero, G. A., Diez, N., and Sevilla, M. (2018). A green route to high-surface area carbons by chemical activation of biomass-based products with sodium thiosulfate. ACS Sust. Chem. Eng. 6, 16323-16331. doi: 10.1021/acssuschemeng.8b03264

Gao, L., Peng, A., Wang, Z. Y., Zhang, H., Shi, Z., Gu, Z., et al. (2008). Growth of aligned carbon nanotube arrays on metallic substrate and its application to supercapacitors. Solid State Commun. 146, 380-383. doi: 10.1016/j.ssc.2008.03.034

Gao, Z., Zhang, Y., Song, N., and Li, X. (2017). Biomass-derived renewable carbon materials for electrochemical energy storage. Mater. Res. Lett. 5, 69-88. doi: 10.1080/21663831.2016.1250834

Gautham Prasad, G., Shetty, N., Thakur, S., Rakshitha, and Bommegowda, K. B. (2019). Supercapacitor technology and its applications: a review. IOP Conf. Ser. Mater. Sci. Eng. 561:012105. doi: 10.1088/1757-899X/561/1/012105

González, A., Goikolea, E., Barrena, J. A., and Mysyk, R. (2016). Review on supercapacitors: technologies and materials. Renew. Sust. Energ. Rev. 58, 1189-1206. doi: 10.1016/j.rser.2015.12.249

González-García, P. (2018). Activated carbon from lignocellulosics precursors: A review of the synthesis methods, characterization techniques and applications. Renew. Sust. Energy Rev. 82, 1393-1414. doi: 10.1016/j.rser.2017.04.117

Gopal Bairi, V., Bourdo, S. E., Nasini, U. B., Ramasahayam, S. K., Watanabe, F., Berry, B. C., et al. (2013). Microwave-assisted synthesis of nitrogen and phosphorus co-doped mesoporous carbon and their potential application in alkaline fuel cells. Sci. Adv. Mat. 5, 1275-1281. doi: 10.1166/sam.2013.1583

Grishechko, L. I., Amaral-Labat, G., Fierro, V., Szczurek, A., Kuznetsov, B. N., and Celzard, A. (2016). Biosourced, highly porous, carbon xerogel microspheres. RSC Adv. 6, 65698-65708. doi: 10.1039/C6RA09462G

$\mathrm{Gu}$, W., and Yushin, G. (2014). Review of nanostructured carbon materials for electrochemical capacitor applications: advantages and limitations of activated carbon, carbide-derived carbon, zeolite-templated carbon, carbon aerogels, carbon nanotubes, onion-like carbon, and graphene: nanostructured carbon materials for electrochemical capacitor applications. Wiley Interdiscip. Rev. Energ. Environ. 3, 424-473. doi: 10.1002/wene.102
Haslam, E. (2007). Vegetable tannins - lessons of a phytochemical lifetime. Phytochemistry 68, 2713-2721. doi: 10.1016/j.phytochem.2007.09.009

Herou, S., Ribadeneyra, M. C., Madhu, R., Araullo-Peters, V., Jensen, A., Schlee, P., et al. (2019). Ordered mesoporous carbons from lignin: a new class of biobased electrodes for supercapacitors. Green Chem. 21, 550-559. doi: 10.1039/C8GC03497D

Hu, L., Zang, L., Yang, J., Liu, Q., Qiao, X., Qiu, J., et al. (2020). A scalable strategy for carbon derived from complex six-membered ring-like tannin on glass fiber for $1 \mathrm{D} / 2 \mathrm{D}$ flexible all solid state supercapacitors. J. Electroanal. Chem. 856:113693. doi: 10.1016/j.jelechem.2019.113693

Hulicova-Jurcakova, D., Seredych, M., Lu, G. Q., and Bandosz, T. J. (2009). Combined effect of nitrogen- and oxygen-containing functional groups of microporous activated carbon on its electrochemical performance in supercapacitors. Adv. Funct. Mater. 19, 438-447. doi: 10.1002/adfm.200801236

IEA (2014). Technology Roadmap Energy Storage.

IEA (2019). Data and Statistics. IEA. Available online at: https://www.iea.org/dataand-statistics (accessed December 12, 2019).

Inagaki, M., Konno, H., and Tanaike, O. (2010). Carbon materials for electrochemical capacitors. J. Power Sourc. 195, 7880-7903. doi: 10.1016/j.jpowsour.2010.06.036

Inagaki, M., Toyoda, M., Soneda, Y., and Morishita, T. (2018). Nitrogen-doped carbon materials. Carbon 132, 104-140. doi: 10.1016/j.carbon.2018.02.024

Inamuddin, Ahmer, M. F., Asiri, A. M., and Zaidi, S. (2018). Electrochemical Capacitors: Theory, Materials and Applications. Millersville, PA: Materials Research Forum LLC.

IOXUS Inc. (2020). Applications. IOXUS. Available online at: https://ioxus.com/ english/applications/ (accessed April 14, 2020).

James, S. L., Adams, C. J., Bolm, C., Braga, D., Collier, P., Friščić, T., et al. (2012). Mechanochemistry: opportunities for new and cleaner synthesis. Chem. Soc. Rev. 41, 413-447. doi: 10.1039/C1CS15171A

Jana, P., Fierro, V., Pizzi, A., and Celzard, A. (2014). Biomass-derived, thermally conducting, carbon foams for seasonal thermal storage. Biomass Bioenergy 67, 312-318. doi: 10.1016/j.biombioe.2014.04.031

Jurewicz, K., Vix-Guterl, C., Frackowiak, E., Saadallah, S., Reda, M., Parmentier, J., et al. (2004). Capacitance properties of ordered porous carbon materials prepared by a templating procedure. J. Phys. Chem. Solids 65, 287-293. doi: $10.1016 /$ j.jpcs.2003.10.024

Kaupp, G. (2009). Mechanochemistry: the varied applications of mechanical bondbreaking. CrystEngComm 11, 388-403. doi: 10.1039/B810822F

Kaupp, G. (2011). Reactive milling with metals for environmentally benign sustainable production. CrystEngComm 13:3108. doi: 10.1039/clce 05085k

Kim, S., Chen, J., Cheng, T., Gindulyte, A., He, J., He, S., et al. (2018). PubChem 2019 update: improved access to chemical data. Nucleic Acids Research 47, D1102-D1109. doi: 10.1093/nar/gky1033

Kim, T.-Y., Lee, K.-R., Eun, K. Y., and Oh, K.-H. (2003). Carbon nanotube growth enhanced by nitrogen incorporation. Chem. Phys. Lett. 372, 603-607. doi: 10.1016/S0009-2614(03)00465-2

Kim, Y.-S., Kumar, K., Fisher, F. T., and Yang, E.-H. (2012). Out-of-plane growth of CNTs on graphene for supercapacitor applications. Nanotechnology 23:015301. doi: 10.1088/0957-4484/23/1/015301

Kötz, R., and Carlen, M. (2000). Principles and applications of electrochemical capacitors. Electrochim. Acta 45, 2483-2498. doi: 10.1016/S0013-4686(00)00354-6

Lacoste, C., Basso, M. C., Pizzi, A., Laborie, M.-P., Garcia, D., and Celzard, A. (2013). Bioresourced pine tannin/furanic foams with glyoxal and glutaraldehyde. Ind. Crops Prod. 45, 401-405. doi: 10.1016/j.indcrop.2012.12.032

Lee, J., Kim, J., and Hyeon, T. (2006). Recent progress in the synthesis of porous carbon materials. Adv. Mater. 18, 2073-2094. doi: 10.1002/adma.2005 01576

Li, J.-G., Ho, Y.-F., Ahmed, M. M. M., Liang, H.-C., and Kuo, S.-W. (2019). Mesoporous carbons templated by PEO-PCL block copolymers as electrode materials for supercapacitors.pdf. Chem. Eur. J. 25, 10456-10463. doi: 10.1002/chem.201901724

Li, S., Pasc, A., Fierro, V., and Celzard, A. (2016). Hollow carbon spheres, synthesis and applications - a review. J. Mater. Chem. A 4, 12686-12713. doi: 10.1039/C6TA03802F 
Libbrecht, W., Verberckmoes, A., Thybaut, J. W., Van Der Voort, P., and De Clercq, J. (2017). Soft templated mesoporous carbons: tuning the porosity for the adsorption of large organic pollutants. Carbon 116, 528-546. doi: 10.1016/j.carbon.2017.02.016

Lide, D. R. ed. (2004). CRC Handbook of Chemistry and Physics, 85th edn. Boca Raton, FL: CRC Press.

Lim, E., Jo, C., and Lee, J. (2016). A mini review of designed mesoporous materials for energy-storage applications: from electric double-layer capacitors to hybrid supercapacitors. Nanoscale 8, 7827-7833. doi: 10.1039/C6NR00796A

Liu, D., Yuan, P., Tan, D., Liu, H., Wang, T., Fan, M., et al. (2012). Facile preparation of hierarchically porous carbon using diatomite as both template and catalyst and methylene blue adsorption of carbon products. J. Colloid Interface Sci. 388, 176-184. doi: 10.1016/j.jcis.2012.08.023

Liu, J., Wickramaratne, N. P., Qiao, S. Z., and Jaroniec, M. (2015). Molecular-based design and emerging applications of nanoporous carbon spheres. Nat. Mater. 14, 763-774. doi: 10.1038/nmat4317

Lu, S., Song, Y., Guo, K., Chen, X., Xu, J., and Zhao, L. (2018). Effect of aqueous electrolytes on the electrochemical behaviors of ordered mesoporous carbon composites after $\mathrm{KOH}$ activation as supercapacitors electrodes. J. Electroanal. Chem. 818, 58-67. doi: 10.1016/j.jelechem.2018.04.025

Maxwell Technologies Inc. (2020). Cells - Overview. Maxwell Technologies. Available online at: https://www.maxwell.com/products/ultracapacitors/cells/ (accessed April 14, 2020).

Mbarki, F., Selmi, T., Kesraoui, A., Seffen, M., Gadonneix, P., Celzard, A., et al. (2019). Hydrothermal pre-treatment, an efficient tool to improve activated carbon performances. Ind. Crops Prod. 140:111717. doi: 10.1016/j.indcrop.2019.111717

Meng, Y., Gu, D., Zhang, F., Shi, Y., Cheng, L., Feng, D., et al. (2006). A family of highly ordered Mesoporous polymer resin and carbon structures from organicorganic self-assembly. Chem. Mater. 18, 4447-4464. doi: 10.1021/cm060921u

Miller, J. R., and Burke, A. F. (2008). Electrochemical capacitors: challenges and opportunities for real-world applications. Electrochem. Soc. Interface 17, 53-57. doi: 10.1201/9781420069709.ch8

Mostazo-López, M. J., Ruiz-Rosas, R., Castro-Muñiz, A., Nishihara, H., Kyotani, T., Morallón, E., et al. (2018). Ultraporous nitrogen-doped zeolite-templated carbon for high power density aqueous-based supercapacitors. Carbon 129, 510-519. doi: 10.1016/j.carbon.2017.12.050

Moussa, G., Hajjar-Garreau, S., Taberna, P.-L., Simon, P., and Matei Ghimbeu, C. (2018). Eco-friendly synthesis of nitrogen-doped mesoporous carbon for supercapacitor application. C 4:20. doi: 10.3390/c4020020

Nasini, U. B., Bairi, V. G., Ramasahayam, S. K., Bourdo, S. E., Viswanathan, T., and Shaikh, A. U. (2014). Phosphorous and nitrogen dual heteroatom doped mesoporous carbon synthesized via microwave method for supercapacitor application. J. Power Sourc. 250, 257-265. doi: 10.1016/j.jpowsour.201 3.11 .014

National Institute for Occupational Safety and Health (2018). NIOSH Pocket Guide to Chemical Hazards. Available online at: https://www.cdc.gov/niosh/ npg/npgsyn-a.html\# (accessed April 24, 2020).

Orazem, M. E., and Tribollet, B. (2008). Electrochemical Impedance Spectroscopy. Hoboken, N.J: Wiley.

Pachauri, R. K., Mayer, L., and Intergovernmental Panel on Climate Change (Eds.). (2015). Climate Change 2014: Synthesis Report. Geneva: Intergovernmental Panel on Climate Change.

Pandolfo, A. G., and Hollenkamp, A. F. (2006). Carbon properties and their role in supercapacitors. J. Power Sourc. 157, 11-27. doi: 10.1016/j.jpowsour.2006.02.065

Paraknowitsch, J. P., and Thomas, A. (2013). Doping carbons beyond nitrogen: an overview of advanced heteroatom doped carbons with boron, sulphur and phosphorus for energy applications. Energy Environ. Sci. 6:2839. doi: $10.1039 / \mathrm{c} 3 e e 41444 \mathrm{~b}$

Pizzi, A. (1982). Condensed tannins for adhesives. Ind. Eng. Chem. Prod. Res. Dev. 21, 359-369. doi: 10.1021/i300007a005

Ra, E. J., Raymundo-Piñero, E., Lee, Y. H., and Béguin, F. (2009). High power supercapacitors using polyacrylonitrile-based carbon nanofiber paper. Carbon 47, 2984-2992. doi: 10.1016/j.carbon.2009.06.051

Ramasahayam, S. K., Nasini, U. B., Shaikh, A. U., and Viswanathan, T. (2015). Novel tannin-based Si, P co-doped carbon for supercapacitor applications. J. Power Sources 275, 835-844. doi: 10.1016/j.jpowsour.2014.11.020
Raymundo-Piñero, E., Cadek, M., and Béguin, F. (2009). Tuning carbon materials for supercapacitors by direct pyrolysis of seaweeds. Adv. Funct. Mater. 19, 1032-1039. doi: 10.1002/adfm.200801057

Salinas-Torres, D., Ruiz-Rosas, R., Morallón, E., and Cazorla-Amorós, D. (2019). Strategies to enhance the performance of electrochemical capacitors based on carbon materials. Front. Mater. 6:115. doi: 10.3389/fmats.2019.00115

Sánchez-Sánchez, A., Fierro, V., Izquierdo, M. T., and Celzard, A. (2016). Functionalized, hierarchical and ordered mesoporous carbons for high-performance supercapacitors. J. Mater. Chem. A 4, 6140-6148. doi: $10.1039 /$ C6TA00738D

Sanchez-Sanchez, A., Izquierdo, M. T., Ghanbaja, J., Medjahdi, G., Mathieu, S., Celzard, A., et al. (2017a). Excellent electrochemical performances of nanocast ordered mesoporous carbons based on tannin-related polyphenols as supercapacitor electrodes. J. Power Sources 344, 15-24. doi: 10.1016/j.jpowsour.2017.01.099

Sanchez-Sanchez, A., Izquierdo, M. T., Mathieu, S., González-Álvarez, J., Celzard, A., and Fierro, V. (2017b). Outstanding electrochemical performance of highly $\mathrm{N}$ - and O-doped carbons derived from pine tannin. Green Chem. 19, 2653-2665. doi: 10.1039/C7GC00491E

Sanchez-Sanchez, A., Izquierdo, M. T., Medjahdi, G., Ghanbaja, J., Celzard, A., and Fierro, V. (2018). Ordered mesoporous carbons obtained by softtemplating of tannin in mild conditions. Microp. Mesop. Mater. 270, 127-139. doi: 10.1016/j.micromeso.2018.05.017

Schlienger, S., Graff, A.-L., Celzard, A., and Parmentier, J. (2012). Direct synthesis of ordered mesoporous polymer and carbon materials by a biosourced precursor. Green Chem. 14, 313-316. doi: 10.1039/C2GC16160E

Selmi, T., Sanchez-Sanchez, A., Gadonneix, P., Jagiello, J., Seffen, M., Sammouda, H., et al. (2018). Tetracycline removal with activated carbons produced by hydrothermal carbonisation of agave Americana fibres and mimosa tannin. Ind. Crops Prod. 115, 146-157. doi: 10.1016/j.indcrop.2018.02.005

Sevilla, M., Diez, N., Ferrero, G. A., and Fuertes, A. B. (2019). Sustainable supercapacitor electrodes produced by the activation of biomass with sodium thiosulfate. Energy Storage Mater. 18, 356-365. doi: 10.1016/j.ensm.2019. 01.023

Sevilla, M., and Mokaya, R. (2014). Energy storage applications of activated carbons: supercapacitors and hydrogen storage. Energy Environ. Sci. 7, 1250-1280. doi: 10.1039/C3EE43525C

Sharma, P., and Bhatti, T. S. (2010). A review on electrochemical double-layer capacitors. Energ. Conv. Manage. 51, 2901-2912. doi: 10.1016/j.enconman.2010.06.031

Shirmohammadli, Y., Efhamisisi, D., and Pizzi, A. (2018). Tannins as a sustainable raw material for green chemistry: a review. Ind. Crops Prod. 126, 316-332. doi: 10.1016/j.indcrop.2018.10.034

SilvaTeam (2018). All About Tannins. Available online at: https://www.silvateam. com/en/who-we-are/extracts-nature/all-about-tannins.html (accessed April 1, 2019).

Szczurek, A., Amaral-Labat, G., Fierro, V., Pizzi, A., and Celzard, A. (2011a). The use of tannin to prepare carbon gels. Part II. carbon cryogels. Carbon 49, 2785-2794. doi: 10.1016/j.carbon.2011.03.005

Szczurek, A., Amaral-Labat, G., Fierro, V., Pizzi, A., Masson, E., and Celzard, A. (2011b). The use of tannin to prepare carbon gels. Part I: carbon aerogels. Carbon 49, 2773-2784. doi: 10.1016/j.carbon.2011.03.007

Szczurek, A., Fierro, V., Pizzi, A., and Celzard, A. (2013). Mayonnaise, whipped cream and meringue, a new carbon cuisine. Carbon 58, 245-248. doi: 10.1016/j.carbon.2013.02.056

Szczurek, A., Fierro, V., Pizzi, A., and Celzard, A. (2014). Emulsion-templated porous carbon monoliths derived from tannins. Carbon 74, 352-362. doi: 10.1016/j.carbon.2014.03.047

Tanaka, S., Fujimoto, H., Denayer, J. F. M., Miyamoto, M., Oumi, Y., and Miyake, Y. (2015). Surface modification of soft-templated ordered mesoporous carbon for electrochemical supercapacitors. Micropor Mesopor Mater. 217, 141-149. doi: 10.1016/j.micromeso.2015.06.017

Tellez-Juárez, M. C., Fierro, V., Zhao, W., Fernández-Huerta, N., Izquierdo, M. T., Reguera, E., et al. (2014). Hydrogen storage in activated carbons produced from coals of different ranks: Effect of oxygen content. Int. J. Hydrogen Energy 39, 4996-5002. doi: 10.1016/j.ijhydene.2014.01.071

Tiruye, G. A., Muñoz-Torrero, D., Berthold, T., Palma, J., Antonietti, M., Fechler, N., et al. (2017). Functional porous carbon nanospheres from sustainable 
precursors for high performance supercapacitors. J. Mater. Chem. A 5, 16263-16272. doi: 10.1039/C7TA01951C

Tondi, G., Fierro, V., Pizzi, A., and Celzard, A. (2009). Tannin-based carbon foams. Carbon 47, 1480-1492. doi: 10.1016/j.carbon.2009.01.041

Tondi, G., and Petutschnigg, A. (2015). Middle infrared (ATR FT-MIR) characterization of industrial tannin extracts. Ind. Crops Prod. 65, 422-428. doi: 10.1016/j.indcrop.2014.11.005

Vivo-Vilches, J., Celzard, A., Fierro, V., Devin-Ziegler, I., Brosse, N., Dufour, A., et al. (2019). Lignin-based carbon nanofibers as electrodes for vanadium redox couple electrochemistry. Nanomaterials 9:106. doi: 10.3390/nano9010106

Vix-Guterl, C., Frackowiak, E., Jurewicz, K., Friebe, M., Parmentier, J., and Béguin, F. (2005). Electrochemical energy storage in ordered porous carbon materials. Carbon 43, 1293-1302. doi: 10.1016/j.carbon.2004.12.028

Wang, G.-W. (2013). Mechanochemical organic synthesis. Chem. Soc. Rev. 42, 7668-7700. doi: 10.1039/c3cs35526h

Wang, J.-G., Liu, H., Sun, H., Hua, W., Wang, H., Liu, X., et al. (2018). One-pot synthesis of nitrogen-doped ordered mesoporous carbon spheres for high-rate and long-cycle life supercapacitors. Carbon 127, 85-92. doi: 10.1016/j.carbon.2017.10.084

Wang, Y., Song, Y., and Xia, Y. (2016). Electrochemical capacitors: mechanism, materials, systems, characterization and applications. Chem. Soc. Rev. 45, 5925-5950. doi: 10.1039/C5CS00580A

Wickramaratne, N. P., and Jaroniec, M. (2013). Phenolic resin-based carbons with ultra-large mesopores prepared in the presence of poly(ethylene oxide)poly(butylene oxide)-poly(ethylene oxide) triblock copolymer and trimethyl benzene. Carbon 51, 45-51. doi: 10.1016/j.carbon.2012.08.007

Xia, Y., Zhang, W., Xiao, Z., Huang, H., Zeng, H., Chen, X., et al. (2012). Biotemplated fabrication of hierarchically porous $\mathrm{NiO} / \mathrm{C}$ composite from lotus pollen grains for lithium-ion batteries. J. Mater. Chem. 22, 9209-9215. doi: $10.1039 / \mathrm{c} 2 \mathrm{jm} 16935 \mathrm{e}$

Xie, J., Yang, P., Wang, Y., Qi, T., Lei, Y., and Li, C. M. (2018). Puzzles and confusions in supercapacitor and battery: theory and solutions. J. Power Sources 401, 213-223. doi: 10.1016/j.jpowsour.2018.08.090

Xin, W., Severino, J., Venkert, A., Yu, H., Knorr, D., Yang, J.-M., et al. (2020). Fabrication and characterization of solid composite yarns from carbon nanotubes and poly(dicyclopentadiene). Nanomaterials 10:717. doi: 10.3390/nano10040717

Zhai, Y., Dou, Y., Zhao, D., Fulvio, P. F., Mayes, R. T., and Dai, S. (2011). Carbon materials for chemical capacitive energy storage. Adv. Mater. 23, 4828-4850. doi: 10.1002/adma.201100984
Zhang, L. L., and Zhao, X. S. (2009). Carbon-based materials as supercapacitor electrodes. Chem. Soc. Rev. 38:2520. doi: 10.1039/b813846j

Zhang, P., Wang, L., Yang, S., Schott, J. A., Liu, X., Mahurin, S. M., et al. (2017). Solid-state synthesis of ordered mesoporous carbon catalysts via a mechanochemical assembly through coordination cross-linking. Nat. Commun. 8:15020. doi: 10.1038/ncomms 15020

Zhao, W., Fierro, V., Fernández-Huerta, N., Izquierdo, M. T., and Celzard, A. (2012). Impact of synthesis conditions of $\mathrm{KOH}$ activated carbons on their hydrogen storage capacities. Int. J. Hydrogen Energy 37, 14278-14284. doi: 10.1016/j.ijhydene.2012.06.110

Zheng, W., Lv, R., Na, B., Liu, H., Jin, T., and Yuan, D. (2017). Nanocellulosemediated hybrid polyaniline electrodes for high performance flexible supercapacitors. J. Mater. Chem. A 5, 12969-12976. doi: 10.1039/C7TA01990D

Zhong, C., Deng, Y., Hu, W., Qiao, J., Zhang, L., and Zhang, J. (2015). A review of electrolyte materials and compositions for electrochemical supercapacitors. Chem. Soc. Rev. 44, 7484-7539. doi: 10.1039/C5CS00303B

Zhu, J., Yang, J., Miao, R., Yao, Z., Zhuang, X., and Feng, X. (2016). Nitrogen-enriched, ordered mesoporous carbons for potential electrochemical energy storage. J. Mater. Chem. A 4, 2286-2292. doi: 10.1039/C5TA 09073C

Zuliani, J. E., Caguiat, J. N., Kirk, D. W., and Jia, C. Q. (2015). Considerations for consistent characterization of electrochemical double-layer capacitor performance. J. Power Sources 290, 136-143. doi: 10.1016/j.jpowsour.2015.04.019

Zuliani, J. E., Tong, S., Jia, C. Q., and Kirk, D. W. (2018). Contribution of surface oxygen groups to the measured capacitance of porous carbon supercapacitors. J. Power Sources 395, 271-279. doi: 10.1016/j.jpowsour.2018. 05.046

Conflict of Interest: The authors declare that the research was conducted in the absence of any commercial or financial relationships that could be construed as a potential conflict of interest.

Copyright (c) 2020 Castro-Gutiérrez, Celzard and Fierro. This is an open-access article distributed under the terms of the Creative Commons Attribution License (CC $B Y)$. The use, distribution or reproduction in other forums is permitted, provided the original author(s) and the copyright owner(s) are credited and that the original publication in this journal is cited, in accordance with accepted academic practice. No use, distribution or reproduction is permitted which does not comply with these terms. 